ISSN: 0213-2087 eISSN: 2444-7080

DOI: http://dx.doi.org/10.14201/shhc2018363570

\title{
LA EXPANSIVIDAD DEL DISCURSO SOBRE EL «DERECHO HUMANO DE SEGURIDAD», UN «DERECHO SÍNTESIS». CONCRECIONES Y ETIOLOGÍA
}

\author{
The Expansion of the Discourse on the \\ "Human Right of Security", a "Right Synthesis". \\ Concretions and Etiology
}

\author{
M. ${ }^{a}$ Esther MARTÍNEZ QUINTEIRO \\ Universidad Portucalense (UPT), jubilada de la USAL \\ est@usal.es
}

Recepción: 27/04/2018 Revisión: 14/05/2018 Aceptación: 28/06/2018

RESUMEN: El "Derecho Humano a la Seguridad" es rico en manifestaciones y acepciones (Derecho a la Seguridad Personal, Jurídica, Patrimonial, Ciudadana, Colectiva, Pública, del Pueblo, Nacional, Internacional, etc.). Sin embargo, su imprecisa enunciación y la de algunas de las múltiples concreciones registradas en los textos propositivos o normativos de Derechos Humanos, o la variabilidad de las recogidas u omitidas en aquellos, dificultan una descripción intemporal del cambiante concepto y contenido de sus «determinaciones» o incluso del «derecho matriz».

En 1793 el "Derecho Humano a la Seguridad" fue definido por los revolucionarios franceses como un "derecho síntesis", que requiere (además de la protección de las personas y sus bienes) la garantía de todos los demás derechos. La ONU echaría mano del potencial sintético del "Derecho a la Seguridad", para subrayar la proclamada indivisibilidad e interdependencia de los Derechos Humanos, de facto tan mal defendidas por la propia Organización como la variable «Seguridad Internacional». En los años 90 del pasado siglo, sus portavoces, para hacer olvidar el fracaso de su objetivo asegurador y reafirmar la indivisibilidad de los Derechos Humanos, promovieron una «re-denominación» del Derecho de Seguridad: El «Derecho a la Seguridad Humana", implicando a la sociedad civil en su defensa y enfatizándolo. 

UN «DERECHO SÍNTESIS». CONCRECIONES Y ETIOLOGÍA

Palabras clave: derechos humanos; seguridad; inseguridad; derecho humano a la seguridad; derecho a la seguridad humana; ONU.

Llama la atención, a punto de cerrase la segunda década del siglo xxi, lo notoriamente acrecida que se halla en el mundo la demanda de seguridad, justamente cuando se detecta una hipertrofia de lo que Foucault define, acertadamente, como «mecanismos de seguridad». Entre ellos cabría incluir los establecidos en su defensa, con mayor o menor operatividad, por la ONU¹, así como los numerosos mecanismos de seguridad privada articulados para suplir las ineficiencias del Estado, teóricamente detentador del monopolio del uso legítimo de la violencia, pero consentidor del deterioro de la convivencia, como hace tiempo señaló Guiddens ${ }^{2}$.

Describir y explicar los contenidos, dimensiones y expansiva evolución discursiva del denominado "derecho humano a la seguridad», que parece corresponderse en el tiempo con el incremento de la percepción de inseguridad, y establecer los posibles nexos entre ambos fenómenos, es sin duda un desafío por muchos conceptos, aun si nos circunscribimos al discurso al respecto de la ONU, que es el consensuado por la sociedad internacional y demandado por la sociedad civil o promovido por los burócratas y técnicos vinculados a la Organización, y que es aquel al que aquí nos referiremos con más detalle, tras repasar sus antecedentes. Lo es por muchas razones:

En primer lugar, porque, aunque en algunos sitios o publicaciones de Naciones Unidas, como ocurre con la web de la Oficina del Alto Comisionado de la ONU para los Derechos Humanos (ACNUDH), se ofrecen explicaciones sobre lo que debe entenderse por Derechos Humanos ${ }^{3}$, en lo que concierne a su funda-

1. Foucault, Michel: Seguridad, territorio, población. Madrid: Akal, 2008, p. 19.

2. Cit. en SÁvio ReIs SouZA, Robson: Quem comanda a segurança pública no Brasil? Belorizonte, MS: Letramento, 2015, p. 141.

3. La medida definición de la ACNUDH en 2017 es esta: "Los derechos humanos son derechos inherentes a todos los seres humanos, sin distinción alguna de nacionalidad, lugar de residencia, sexo, origen nacional o étnico, color, religión, lengua, o cualquier otra condición. Todos tenemos los mismos derechos humanos, sin discriminación alguna. Estos derechos son interrelacionados, interdependientes e indivisibles. Los derechos humanos universales están a menudo contemplados en la ley y garantizados por ella, a través de los tratados, el derecho internacional consuetudinario, los principios generales y otras fuentes del derecho internacional». [Cit. en ACNUDH: “¿Qué son los derechos humanos?». Disponible en <http:// www.ohchr.org/ SP/Issues/Pages/ WhatareHumanRights.aspx> (C. 1-09-2017). El subrayado en cursiva es nuestro]. Nótese que en el texto acotado se elude definir los derechos humanos como garantías jurídicas, solo se dice que están juridificados «a menudo», así pues no necesariamente lo están, lo que parece una apuesta matizada por el iusnaturalismo. El Folleto Informativo n. 32 sobre Los derechos humanos, el terrorismo y la lucha contra el terrorismo, disponible en $<$ http://www.ohchr. org/Documents/Publications/Factsheet32sp.pdf> (C. 4-08-2017), producido por esta misma Oficina en 2008, nadaba tranquilamente entre dos aguas al afirmar: «Los derechos humanos son valores universales y garantías juridicas que protegen a personas y grupos contra acciones y omisiones primordialmente de agentes del Estado que interfieren con las libertades fundamentales, los derechos y la dignidad humana...». Sin embargo, la ACNUDH no mantiene una postura unívoca y en el pasado (2006) ha hecho públicos textos de connotaciones inequívocamente positivistas, en que se responde a la pregunta sobre qué son los derechos humanos, por ejemplo así: "Los derechos humanos son garantías jurídicas 

UN «DERECHO SÍNTESIS». CONCRECIONES Y ETIOLOGÍA

mentación éstas son a menudo intencionadamente ambiguas, o se o contradicen, y la ONU sigue sin definir, como señalaba hace unos años Maximiliano Prado, que ha de entenderse por "derecho humano" en sus documentos jurídicos ${ }^{4}$, combinando con posibilismo fundamentaciones o posiciones iusnaturalistas y iuspositivistas para englobar en dicha categoría ciertos valores o principios, en según qué textos. En algunos de ellos se califica de "derecho humano" a aquel que se propone o declara como tal, pero no está positivado, pese a las protestas de los iuspositivistas sobre la pertinencia de semejante encasillamiento (para ellos, como es sabido, no procede denominar "derecho" al que no tiene garantía jurídica). En otros textos, se califica de "derecho humano" aquella prerrogativa o facultad universal e inalienable de personas y/o colectivos, que, por haber sido recogida en Pactos y Convenios Internacionales de obligado cumplimiento, forma parte, propiamente, del Derecho Público Internacional de los Derechos Humanos 5 .

En consecuencia con lo antedicho, coexisten en la ONU, de forma a veces confusa para el analista o investigador de los documentos producidos por la antedicha Organización, o, y, sobre todo, de las manifestaciones efectuadas por sus burócratas o portavoces, dos "discursos» sobre los Derechos Humanos y sus supuestas o establecidas derivas, como ocurre hoy, de forma muy notoria, con el Derecho Humano de Seguridad. Son ambos discursos funcionalmente distintos, aunque en principio complementarios y con vocación de fusión: el discurso "propositivo» $\mathrm{o}$ "declarativo", con un potencial legitimador y transformador no despreciable, pese a no ser vinculante, tiene una función orientadora, pedagógica y anticipadora (pudiendo incluso devenir en derecho consuetudinario), mientras el «discurso normativo", o jurídico, presente en Convenciones, Pactos y Acuerdos, tiene una función, además y primordialmente, ordenadora. Aunque el "discurso" presente en Recomendaciones, Declaraciones, Resoluciones no vinculantes, y en la argumentación legitimadora de ciertos programas de políticas públicas internacionales o

universales que protegen a los individuos y a los grupos contra acciones y omisiones que interfieren con las libertades y los derechos fundamentales y con la dignidad humana. La legislación en materia de derechos humanos obliga a los gobiernos (principalmente) y otros titulares de deberes a hacer ciertas cosas y les impiden hacer otras". [Cit. en ACNHDH: Preguntas frecuentes sobre el enfoque de derechos bumanos en la cooperación para el desarrollo. ONU: New York, Genève, 2006, disponible en <http:// www.ohchr.org/Documents/Publications/FAQsp.pdf> (C. 1-09-2017)].

Sobre el dilema teórico de cómo encajar los derechos naturales en los moldes del iuspositivismo puede verse Ramos Pascua, José Antonio: "Teoría positivista del Derecho y derechos naturales en $\mathrm{H}$. L. A. HART", Anuario de Derechos Humanos. Nueva Época, vol. 12, 2011, pp. 331-364. <http://dx.doi. org/10.5209/rev_ANDH.2011.v12.38108> (C. 5-08-2017)

4. Martínez Quinteiro, M. ${ }^{a}$ Esther: «El discurso de los derechos humanos en perspectiva histórica: el síndrome de la Torre de Babel». En: Pando Ballesteros, M. ${ }^{a}$ Paz; Garrido Rodríguez, Pedro; Muñoz Ramírez, Alicia (eds. y dirs.): Pasado y presente de los derechos humanos. Mirando al futuro. Madrid: La Catarata, 2016, nota 3, p. 56.

5. UNESCO: «Más sobre la naturaleza y el estatus de los instrumentos legales y programas». Ciencias Sociales y Humanas. Disponible en <http://www.unesco.org/new/es/social-and-human-sciences/ themes/advancement/networks/larno/legal-instruments/nature-and-status/> (C. 12-08-2017). 
M. ${ }^{a}$ ESTHER MARTÍNEZ QUINTEIRO

LA EXPANSIVIDAD DEL DISCURSO SOBRE EL "DERECHO HUMANO DE SEGURIDAD», UN «DERECHO SÍNTESIS». CONCRECIONES Y ETIOLOGÍA

planes de acción de la ONU, al que estamos denominado "discurso propositivo", no debiera contradecir en principio al "discurso normativo», si tal cristalización se produce, pudiera darse tal contradicción y, por otra parte, de facto ocurre que el Derecho Público Internacional de los Derechos Humanos no recoge (al menos simultáneamente) todos los denominados (impropiamente para algunos) «derechos» enunciados en el "discurso propositivo".

El investigador tiene que estar atento al tipo de texto, instrumento, o documento internacional de la ONU que utiliza para no confundir el discurso ético, político, o prejurídico, de los derechos humanos, con el discurso jurídico sobre los tales derechos, producido en este mismo marco, pues sus connotaciones no son iguales. Procediendo metodológicamente a este deslinde, nuestra hipótesis es que, si hacemos un seguimiento de ambos tipos de discursos, quedará patente cierta parquedad o insuficiencia de los desarrollos específicamente normativos de la ONU sobre el "derecho humano de seguridad" y sus diferentes dimensiones, mientras resulta llamativa la aparente expansividad de los desarrollos orientativos o declarativos generados en torno al así denominado, los cuales culminan con el intento de reformular, consensuar e implementar, en el siglo xxi, un nuevo concepto del derecho humano a la seguridad -multidimensional y omnicomprensivo de todos los demás derechos universales (un derecho síntesis, como el proclamado derecho a la paz de los últimos tiempos ${ }^{6}$ - a impulsos de la ONU, y a veces de la sociedad civil, o de los teóricos del desarrollo.

En el 2004 el Grupo de Alto Nivel sobre las Amenazas, los Desafíos y el Cambio, convocado por el Secretario General de la ONU, argumentó, en su Informe Un mundo más seguro: la responsabilidad que compartimos ${ }^{7}$, que tanto la ampliación del concepto del Derecho Humano a la Seguridad (en concreto la creación de la denominación "Seguridad Humana») como las reformas institucionales de la ONU necesarias para garantizarla, eran una respuesta a las «nuevas amenazas del siglo XXI», no previsibles, o no previstas, en 1948, momento en que se elaboró la Declaración Universal de los Derechos Humanos. Esto, que se repite a menudo, implicaría una relación de causa-efecto entre el crecimiento de la inseguridad colectiva real (algo distinto de la percibida) y la expansividad del discurso propositivo del Derecho Humano de Seguridad y ciertas nuevas políticas públicas de seguridad internacional conexas con aquel, promovidas por las Naciones Unidas, aunque no estrictamente ejecutadas directamente por la misma Organización, o no sólo por ella, relación que, en nuestra opinión, como intentaremos demostrar después, no se ajusta a la realidad.

El desafío analítico que implica la investigación de la producción discursiva sobre el "Derecho humano de Seguridad" y la de su imparable progresividad,

6. Alemany Briz, Jesús María: "La paz ¿un derecho humano?», Revista Aragonesa de Administración Pública, n. ${ }^{\circ}$ extra 2, 1998, pp. 17-46.

7. ONU: Un mundo más seguro: la responsabilidad que compartimos. Informe del Grupo de Alto Nivel sobre las amenazas, los desafíos y el cambio (A/59/565), de 2 de diciembre de 2004, pp. 1-141. 
desafío derivado en parte de las dualidades que hemos subrayado más arriba, se incrementa en segundo lugar porque el mismo concepto de «seguridad», objeto señalado de dicho Derecho, es, en las Ciencias Sociales, bastante impreciso ${ }^{8}$, lo que obliga a ejercicios hermenéuticos no siempre coincidentes o compartidos para precisar su contenido y exigencias coyunturales en contextos concretos. Incluso, aunque no en toda ocasión, se mantienen la polisemia y la indeterminación relativas cuando ponemos a la «seguridad" un calificativo que la acota, por ejemplo si hablamos de "seguridad jurídica», pues aun siendo quizás esta la que concite una mayor conformidad sobre su significado, el acuerdo no es nunca total ${ }^{9}$. Mayor resulta la carga de ambigüedad que arrastra, en cuanto a contenidos, la "seguridad pública», de la que sabemos que el Estado tiene en todo caso que ocuparse, pero que, a lo largo de la Historia, y aún hoy, resulta potencialmente imprecisa, como muy bien demuestra Ricard Brotat i Jubert ${ }^{10}$, una imprecisión que permanece, aunque se atenúe, incluso si, para evitar interpretaciones autoritarias de la exigencia de esta última (como la de la mera procura de "sometimiento a la norma», aunque no fuera democrática) sustituimos dicha denominación por la de "seguridad ciudadana»,

8. A veces se define la "Seguridad", de una forma un tanto imprecisa, como ausencia real y percibida de riesgos, pero, como subraya Mario Laborie: «en el lenguaje de las Ciencias Sociales «seguridad» es un concepto controvertido, ya que no existe un consenso generalizado sobre su significado. En función de las personas, sus ideas, cultura, y percepciones de la realidad, el término "seguridad" adquiere un valor distinto». Cit. en Laborie IgLesias, Mario: "La evolución del concepto de seguridad». TCol. DEM, Documento Marco 05/2011, Ministerio de Defensa. Madrid: Instituto Español de Estudios Estratégicos, junio de 2011, p. 1. Disponible en <http:// www.ieee.es/Galerias/fichero/docs_marco/2011/DIEEEM05-2011. Evolución Concepto Seguridad. pdf/> (C. 2 de mayo de 2017).

En la misma línea se pronuncian Escobar, Santiago; Muniz, Jacqueline; Sanseviero, Rafael, Fabián SAIN, Marcelo y ZACchi, José Marcelo, cuando afirman: "Definir la seguridad en sociedades heterogéneas, complejas y habituadas a vivir con cuotas altas de incertidumbre no es tarea sencilla, más aún si la definición debe proveer grados suficientes de racionalidad para entregar una orientación adecuada a aquellas políticas gubernamentales que inciden en aspectos tan importantes como una pertenencia integrada y sin zozobras de los ciudadanos a la vida social política del país» (Cit. en "La seguridad ciudadana como politica de estadon. Pro/Sur, n. ${ }^{\circ}$ 4: Fundación Friedrich Ebert, enero 2005, p. 11).

9. "Como la mayoría de los conceptos abstractos, definir el término de seguridad jurídica [subrayaba Adriana Terán Enríquez] resulta complejo por la ambigüedad en la que podemos caer al hablar de ello. Varios autores han hecho intentos al efecto. Henrik Henkel ha dicho que «es la exigencia dirigida al Derecho positivo de crear certeza ordenadora", Helmut Coing la define sencillamente como "la seguridad que proporciona el Derecho", Gustav Radbruch como "la seguridad del Derecho mismo» (de su exigibilidad), mientras que Lon L. Fuller afirma que es "la moral que hace posible al Derecho», López de Oñate le llama "el "jugo vital" del que se alimenta lo que concebimos como el Estado de Derecho". A este respecto Luhmman expresa que la seguridad del Derecho debe consistir, en primer lugar, y ante todo, en la seguridad de que los asuntos, si así se desea, se traten exclusivamente con el código del Derecho y no de acuerdo con el código del poder o de cualquier otro interés no contemplado por el Derecho». Cit. textual en TERÁN EnRíQuez, Adriana: Justicia y crimen en la Nueva España del siglo XVIII. México: Porrua, 2007, pp. 2-3.

10. En Un concepto de seguridad ciudadana (Artículo inédito), disponible en <http://formacion. diputacionalicante.es/default.aspx?lang=es\&ref=almacen\&id Recurso=87> (C. 11-03- 2011). 
acepción utilizada a veces como sinónimo ${ }^{11}$. Este último término, preferido por las organizaciones internacionales por sus connotaciones supuestamente democráticas (en cuanto sugiere que lo que con ella se protege son las prerrogativas de los ciudadanos, sujetos de derechos) es rechazado a veces en las democracias americanas recuperadas en los años 80, por haber sido utilizado en los años 70 por las fuerzas armadas formadas en la "Escuela de las Américas» como alternativa eufemística al de "seguridad nacional», con la intención de intentar «legitimar», con tal impropio y desnaturalizador circunloquio, represiones, torturas y asesinatos del señalado como "enemigo interior" ${ }^{12}$. Entre tanto, hoy, los esfuerzos por depurar el concepto de "seguridad nacional» de los contenidos fundamentalmente militares que predominaron durante la Guerra Fría, que motivaron el oportunista descarte antedicho $^{13}$, y por ampliarlo, va dotando a esta última de contornos cambiantes, pudiendo modificarse sus significados y objetivos en relación al tiempo y al lugar en que tales términos se empleen, incluso dentro de un mismo país, e incluir entre los objetivos a atender o corregir desde la misma factores condicionantes, socioeconómicos, como la pobreza, la desigualdad, etc. o de otra índole, antes impensables para el caso $^{14}$.

11. Véase este uso indistinto, por ejemplo, en el documento español Estrategia de Seguridad Nacional. Un proyecto compartido, 2013, que subraya literalmente: «El mandato constitucional de garantizar la convivencia democrática dentro del marco de la Constitución y del resto del ordenamiento jurídico y de proteger a los ciudadanos en el libre ejercicio de sus derechos y libertades públicas se facilita en nuestro país mediante un sistema de seguridad pública apoyado fundamentalmente en dos cuerpos estatales, uno de naturaleza civil -el Cuerpo Nacional de Policía- y otro de naturaleza militar -la Guardia Civil-, que, junto a policías autonómicas y locales, tienen la responsabilidad del mantenimiento de la seguridad ciudadana». Cit. en Presidencia de Gobierno, Gobierno de España: Estrategia de Seguridad Nacional Un proyecto compartido, 2013, disponible en <http://www.dsn.gob.es/es/estrategiaspublicaciones/estrategias/estrategia-seguridad-nacional>. (C. 15-01-2017).

12. Idem nota anterior, p. 4 .

13. En el contexto de la Guerra Fría el diplomático George Keenam definió la «seguridad nacional» como "la capacidad continuada de un país para sostener el desarrollo de su vida interna sin interferencia seria o amenaza de interferencia de potencias extranjeras». Su objetivo era entonces preservar la unidad e integridad territorial del Estado desarrollando la fortaleza armamentística y militar necesarias a tal fin y orientando en tal sentido su política exterior (CORTE IBáÑEz, Luis de la, y BlanCo NavarRo, José María: Seguridad Nacional, amenazas y respuestas. Madrid: Lid Ed. Empresarial, 2014. Cit. en CALvo, Roberto: La Doctrina Militar de la Seguridad Nacional. Caracas-San Cristóbal: Universidad Católica Andrés Bello, 1979, disponible en <http://lasa.international.pitt.edu/Lasa2001/ UgarteJoseManuel.pdf> (C. 12-05-2017).

14. España ha elaborado, por ejemplo, varios Proyectos Estratégicos sucesivos de «Seguridad Nacional» (2011, 2013, 2017), que comienzan por precisar y readaptar en función de los tiempos y necesidades, desde una visión integral, los contenidos objetivos y prioridades de la que definen como un "servicio público», en función de los riesgos y amenazas detectados y previstos (en 2013 «los conflictos armados, el terrorismo, las ciberamenazas, el crimen organizado, la inestabilidad económica y financiera, la vulnerabilidad energética, la proliferación de armas de destrucción masiva, los flujos migratorios irregulares, el espionaje, las emergencias y catástrofes, la vulnerabilidad del espacio marítimo y la vulnerabilidad de las infraestructuras críticas y los servicios esenciales»), pero también los factores socioeconómicos, culturales y tecnológicos que los condicionan o alimentan: «el cambio climático, la pobreza, la desigualdad, los extremismos ideológicos, los desequilibrios demográficos o la generalización del uso 

UN «DERECHO SÍNTESIS». CONCRECIONES Y ETIOLOGÍA

Sin embargo, como subraya Ricard Brotat, el concepto de seguridad utilizado por el legislador, el político, el activista, y el de cada una de las adjetivaciones anexas, especialmente las plasmadas en los textos normativos, no es baladí, "puesto que en función del concepto de seguridad del que nos dotamos, determinaremos la política de seguridad necesaria "15.

Dado que la inseguridad forma siempre parte ineludible de la vida de todo ente mortal, si bien en grado variable, se comprende que la dificultad de precisar los límites y contornos de la «seguridad» no impida constatar la previsible permanencia en el tiempo y la omnipresencia espacial de la aspiración a disfrutar de lo que cada colectivo entiende por la misma, aun comprobando que cambian las recetas para conseguirla.

Cuando hacemos un seguimiento de la forma en que se concreta la búsqueda de seguridad, llama a la atención que, mientras que algunos se afanan por ampliar conceptualmente el derecho humano a la misma, para incluir en él, y proclamar desde él, la exigibilidad de prácticamente todos los derechos humanos, como mejor manera de responder a su crecientemente pluridimensionada y exigente demanda, opten otros (entre ellos los fundamentalistas punitivistas) por desacreditar los instrumentos de derechos humanos, denunciando su inutilidad aseguradora, cuando no sus supuestas contrapartidas paralizantes de medidas de protección que consideran más efectivas.

Tras los ataques terroristas experimentados en Estados Unidos y Europa al inicio del milenio -recuerdan Azaola, Aguilar y Barrena- «las políticas públicas han sido dirigidas a la atención de aspectos de seguridad y las medidas adoptadas han tenido un efecto directo en el derecho penal sustantivo y procesal. Desde el argumento de amenaza a la seguridad, el sistema ordinario de justicia penal en su conjunto ya no parece suficiente para hacer frente al peligro. Los desafíos al derecho a un juicio justo y otros derechos humanos bajo el esquema de protección a la seguridad es un fenómeno global no reciente pero sí latente» ${ }^{16}$.

Pero precisamente, en parte porque cabe que la inseguridad sea un hecho, pero es también una percepción que puede ajustarse a riesgos reales y plausibles,

\footnotetext{
nocivo de las nuevas tecnologías», en 2013 (ver Presidencia de gobierno, gobierno de España, Estrategia de Seguridad Nacional, cit.). En 2017 se añaden "otros desafíos de calado, algunos propios, como la necesidad de perseverar en la senda del crecimiento inclusivo o problemas de cohesión territorial», en clara alusión a la crisis política generada por la Declaración Unilateral de la Independencia por el parlamento de Cataluña, el 27 de octubre de 2017. La «Estrategia de Seguridad Nacional 2017» ha sido aprobada por el Gobierno el día 1 de diciembre de 2017 (ver La Moncloa: Estrategia de seguridad nacional, 2017, disponible en <http://www.lamoncloa.gob.es/ serviciosdeprensa/notasprensa/presidenciadelgobierno/ Documents/2017.1824_Estrategia_de_Seguridad_Nacional_ESN_doble_pag.pdf> (C. 3-12-2017).

15. Idem., p. 6.

16. Azaola Garrido, Elena; Agullar García, Ana Dulce y Barrena Nájera, Guadalupe: Los derechos humanos frente a la seguridad nacional y la violencia: una reflexión necesaria. México: Comisión de Derechos Humanos del Distrito Federal, 2016, disponible en <http://cdhdf.org.mx/wp-content/ uploads/2015/06/seguridad-nacional.pdf> (C. 5-04- 2017).
} 
M. ${ }^{a}$ ESTHER MARTÍNEZ QUINTEIRO

LA EXPANSIVIDAD DEL DISCURSO SOBRE EL "DERECHO HUMANO DE SEGURIDAD», UN «DERECHO SÍNTESIS». CONCRECIONES Y ETIOLOGÍA

o ser desmesurada, o incluso gratuita, y revestir formas muy variables, la respuesta a la inseguridad no es unívoca, ni está predeterminada.

Una sociedad que desconoce estar en riesgo, simplemente no responderá en modo alguno al mismo, por real y grave que sea aquel. Dependiendo del momento y de la naturaleza y dimensión de las inseguridades temidas o conocidas, y también del grado de seguridad al que se aspira, o del de inseguridad que se considere normal soportar, los seres humanos o los colectivos sociales pueden optar bien por afrontar la inseguridad empoderándose y reclamando respeto y libertades, y reivindicar la seguridad como un derecho, o bien por someterse al poder, amenazante o protector, renunciando a la libertad. La primera alternativa, más sofisticada que la segunda, solo tuvo oportunidad de intentar imponerse (que no es lo mismo que lograrlo) como opción preferente a partir de la Edad Moderna, cuando surge el discurso de los derechos humanos y en el marco del mismo. Aunque no podía presumirse que así fuera inexorablemente, durante un tiempo pareció que el mundo podría avanzar, aunque no al unísono, ni de forma lineal, o sin coyunturales retrocesos, en esa dirección.

Por contra, hoy, la extendida preocupación por el aumento de inseguridades percibidas como no soportables, y la creciente priorización de la seguridad sobre otros valores y aspiraciones ${ }^{17}$, amenaza la implementación del Derecho Público Internacional de los Derechos Humanos y debilita el discurso articulado en su defensa, paradójicamente concebido desde sus orígenes como un instrumento al servicio de la seguridad personal, la seguridad nacional (la de cada país) o la internacional global (si somos capaces de llegar a acuerdo sobre qué ha de entenderse por tal $\cos ^{18}$ ). Cabe suponer, por sus inevitables y evidentes imbricaciones, que estas tres dimensiones de la seguridad, las entendamos como las entendamos, sean concebidas como objetivos indisociables. Sin embargo no siempre fue así, y, por el contrario, la seguridad personal y la pública y la libertad individual aparecían como una antinomia en la Edad Antigua, la Edad Media y en buena parte de la Edad Moderna, pareciendo a veces incluso hoy que estuviéramos volviendo a la época en que esa percepción de colisión de las diferentes dimensiones de la seguridad prevalecía, imponiendo opciones que deterioran la seguridad personal.

En la Edad Antigua la seguridad, precaria, no era desde luego concebida como un derecho subjetivo, por más que fuera considerada alguna forma de la misma necesaria y se buscara la manera de que la colectividad pudiera disfrutarla. Señalan algunos ${ }^{19}$, que se dio entonces incluso una anticipación de la «seguridad jurídica" y aún una afirmación de su exigibilidad, en la Ley de las Doce Tablas, dada

17. Cossarini, P.: "Miedo y espacios de seguridad: Hobbes y el siglo XXI», Bajo Palabra. Revista de Filosofía. II Época, n. ${ }^{\circ}$ 5, 2010, pp. 229-238, Madrid, Universidad Autónoma, disponible en <https:// revistas.uam.es /bajopalabra/article/view/3465/3679> (C. 1-09-2017).

18. Sotomayor Velásquez, Arturo, "La seguridad internacional: vino viejo en botellas nuevas (International security: old wine in new bottles)», Revista de Ciencia Política, vo. 27, n. ${ }^{\circ} 2,2007$, pp. 67-88.

19. NúÑEz Paz, María Isabel: Derecho Romano, derecho común y contratación en el marco de la Unión Europea. Oviedo: Publicaciones de la Universidad, 2000, p. 97. 

UN «DERECHO SÍNTESIS». CONCRECIONES Y ETIOLOGÍA

en Roma, a mediados del siglo v a. C., para que «la plebe» supiera a qué atenerse en materia normativa y pudiera así evitar que cayera sobre su cabeza el peso de la ley, elaborada por los patricios, por desconocerla. Sin embargo, los escasos textos que en la Edad Antigua o Media teorizan sobre las implicaciones jurídico-políticas de la seguridad no la defienden como una prerrogativa de las personas, sino como un bien, una necesidad o una aspiración de la comunidad que hace imprescindible el Ordenamiento Jurídico, y por tanto lo legitima, convirtiendo en un deber de los que por él se rigen obedecer las Leyes que el colectivo ha acordado darse o consiente. Deber que hay que cumplir aún si fueran injustas las consecuencias que de una aplicación inmerecida se deriven para un ciudadano, para evitar dañar a la comunidad, sumiéndola en la anomia, y por tanto, se entiende, en la inseguridad, hace decir a Sócrates Platón, en sus Diálogos (Critón) ${ }^{20}$, a mediados del siglo iv a. C. Cicerón insistirá, a mediados del siglo i a. C., en diferentes textos ${ }^{21}$ en la bondad y función aseguradora de las leyes, que "no son sino las reglas establecidas, elaboradas y puestas en vigencia, que se hicieron para bien de los ciudadanos y de los Estados, y con vista a la seguridad, la tranquilidad y la felicidad de los hombres, ya que el Derecho no se funda en convenciones, sino en la naturaleza, siendo obedecerlas, obedecer la "recta razón”»22. Pero aunque Cicerón defendiera la existencia de un Derecho Natural ${ }^{23}$, legitimador de las normas de la República, garante de la seguridad colectiva, ni pensaba en la seguridad individual ni creía en la universalidad de derecho individual alguno. La paz social dependería para él

20. Platón: Diálogos. Critón. Madrid: Gredos, 2006, pp. 190-211.

21. De República, escrita entre el 55 y el 51 a. C., y De Legibus, del 52 a. C.

22. Sued, Gazir, Genealogía del Derecho Penal. Tomo I, Volumen 1, San Juan de Puerto Rico: La Grieta, 2015, p. 265.

23. "Todo el discurso de Cicerón- afirma textualmente José María García León- no tiene otra finalidad que el intento de legitimación del Estado Romano, al que considera en su forma republicana como ideal, tanto desde el punto de vista histórico (compendio de los aciertos de otros pueblos y de sus particularidades propias) como social (expresión de la justicia), recurriendo a un conjunto de categorías ideológicas y morales (ley, justicia, virtud) que fundamentan la teoría del bien común. Su aportación teórica, la defensa del derecho como forma jurídica del Estado, estaba en consonancia con las condiciones su tiempo, en la medida en que el Estado Romano necesitaba de una legitimación, justificación jurídica basada en el Derecho, en que basar el dominio de las clases que se aprovechaban tanto de la explotación económica como de la opresión política a que sometían a las clases y pueblos explotados. En su contexto histórico aparece como un logro social, el sometimiento de las relaciones individuales al interés general, aunque en realidad es el tratamiento jurídico de las contradicciones sociales para tratar de legitimar y amortiguar los conflictos entre clases; presupone, por tanto, el reconocimiento de la desigualdad social que se pretende legitimar y mantener en nombre de las leyes de la naturaleza (la esclavitud es una institución basada en la naturaleza, que hace a unos hombres superiores a otros)». Texto de García León, José María: «Cicerón: El concepto de Estado», Laberinto, n. ${ }^{4}$, 2000, p. 9. Disponible en <http://laberinto.uma.es/> (C. 12-01-2016)

En De Legibus, obra escrita en el año 52 a. C., Cicerón defendió que las leyes deben basarse en la razón, pero dicha obra no es más que el intento de naturalizar la primacía de las clases dirigentes (que a él le parecía lo «razonable» y por tanto lo «natural»). Para la función conservadora y legitimadora del Derecho Objetivo del Derecho Natural en Cicerón puede verse Utchenko, L.: Cicerón y su tiempo. Madrid: Akal, 2005, p. 213 y ss. 
M. ${ }^{a}$ ESTHER MARTÍNEZ QUINTEIRO

LA EXPANSIVIDAD DEL DISCURSO SOBRE EL "DERECHO HUMANO DE SEGURIDAD», UN «DERECHO SÍNTESIS». CONCRECIONES Y ETIOLOGÍA

del sometimiento del individuo a lo que entendía por interés general (el mantenimiento del statu quo $)^{24}$.

Durante la turbulenta Edad Media, en la que la inseguridad era el "pan nuestro de cada día", muchos depositaron en la religión sus esperanzas de salvación o amparo, y mientras la conquista del cielo pareció lejana, a cambio de seguridad personal aceptaron con resignación en la tierra someterse a los poderes múltiples, fueran estos las autoridades eclesiásticas o los señores feudales, o doblegarse a normas de colectivos que los encorsetaban pero los protegían, como los gremios y las corporaciones.

Frente a la atomización del poder, iniciándose la crisis la del feudalismo, en el siglo xiII, Santo Tomás deposita su confianza en la ley humana, inspirada en el Derecho Natural y, a través de éste, en el Divino ("prescripción de la razón en orden al bien común) promulgada por el que tiene el cuidado de la comunidad", es decir en manos de uno, las de un monarca ${ }^{25}$, y no de muchos, como mejor garante de la seguridad colectiva, desiderátum que aspirará a cumplir, más tarde, la Monarquía Absoluta.

Ajena aún al principio del «derecho individual a la seguridad jurídica» de las personas, pero precisada de legitimación, la Monarquía Absoluta se erigió, en efecto, entre los siglos XVI y XVIII, en garante de la «seguridad pública», entendida como protección de la paz y tranquilidad de los habitantes del Reino, de sus espacios territoriales, sus transacciones comerciales y sus vías de comunicación y transporte, caminos y mares, creando instituciones y fuerzas como corporaciones armadas, ejércitos, tribunales, administraciones, diplomacia, etc., destinadas a garantizarla, y se preocupó no solo de la supervivencia del propio Estado y de la defensa del mismo frente al exterior, sino también de la protección, frente a terceros, de la vida, las propiedades y el bienestar de los gobernados, puniendo, o intentando hacerlo, a quienes pusieran en peligro tales cosas, pero también vigilando y procurando evitar el ataque a las mismas ${ }^{26}$. Sin embargo, la voluntad de control y de monopolio de poder de la Monarquía Absoluta, teóricamente protectora del "orden social", y la imposición de leyes penales crueles y desproporcionadas como instrumento de ese poder ${ }^{27}$, era al mismo tiempo fuente de inseguridad personal.

24. La ley humana tendrá fuerza de tal en la medida en que deriva de la Ley Natural, y «si en algo está en desacuerdo con la Ley Natural, ya no es ley, sino corrupción de la ley». Siendo la Ley Natural participación de la Ley Eterna en la criatura racional, la ley humana tiene su último fundamento en la Ley Eterna. SAnto Tomás DE Aquino: Suma Teológica I-II. Cuestión 95, artículo 2. Disponible en <http:// hjg.com.ar/sumat/b/c95.html> (C. 8-08-2017)

25. González Ruiz, Samuel; López Portillo V., Ernesto; Yáñez R., José Arturo: Seguridad pública en México: problemas, perspectivas y propuestas. México: Universidad Autónoma, 1994, p. 25. 157

26. Tomás y Valiente, F.: El Derecho Penal de la Monarquía Absoluta. Madrid: Tecnos, 1992, p.

27. «La Ley humana [sostiene en sus Relecciones el P. Vitoria] proviene de Dios; luego obliga del mismo modo que la Ley divina. Que la Ley humana proviene de Dios se prueba porque no solo se llama obra de Dios lo que Él por sí mismo produce, sino también lo que hace por medio de causas segundas. Luego no sólo debe llamarse ley divina la que sancionó él mismo, sino además la que con 
La aparición del discurso moderno sobre el Derecho Natural no significó una reconversión al unísono y sin fisuras de los iusnaturalistas hacia una firme defensa del derecho a la seguridad individual, ni una ruptura unánime con las concepciones clásicas de dicho Derecho, que habían servido para apuntalar el poder, propiciando algunos bandazos teóricos, aunque los primeros discursos de los defensores de derechos individuales "naturales" y los textos fundantes del discurso elaborado en su defensa en los albores de la Edad Moderna, revelan que los derechos humanos fueron concebidos ya en el arranque de dicha etapa histórica como una herramienta volcada en una medida muy importante a la búsqueda de la seguridad personal, incluida la seguridad de la libertad y de la vida o del disfrute de los propios bienes, amenazada por terceros, pero también por las Monarquías que pugnaban por monopolizar todos los resortes del poder.

En el siglo XVI el Padre Vitoria, fundador de la Escuela de Salamanca, artífice de un novedoso discurso sobre el carácter natural de los derechos humanos, no niega la legitimidad del poder del Monarca y por tanto, en última instancia, de la Ley $^{28}$, necesariamente emanada del Monarca, en cuanto él es el que tiene a su cargo el cuidado de la comunidad ${ }^{29}$, y ha de actuar guiado por la razón, que le permite conocer la ley natural y seguirla. De ello se sigue, según Vitoria, la obligación de los súbditos de obedecer la ley humana y no solo la divina, pero recuerda que la primera debe orientarse, y necesariamente se orienta, al bien común, al no ser lícito (ni posible) al príncipe establecer una ley que no atienda al mismo:

"Que la ley se ordena al bien común [dice textualmente el P. Vitoria], puede entenderse en dos sentidos: Uno "de derecho", porque así debe ser, y otro "de hecho', porque, si no es así, no es ley”»30.

Sin embargo, la preocupación del fundador de la Escuela de Salamanca por la paz y tranquilidad públicas es tal, que defenderá la obligación de cumplir las leyes, a condición de que sean convenientes a la república, "aunque las disponga un tirano, precisamente» por la seguridad que aportan:

Ciertamente [argumenta] parece que las leyes que son convenientes a la república obligan, no porque él las sancione, sino por el consentimiento de la República, por ser más seguro guardar las leyes dadas por el tirano que el vivir sin ningunas.

Sin duda [reflexiona el ilustre dominico] cedería en ruina evidente de la República que no bubiera juicios ni modo de castigar a los malhechores.

el poder de Dios dispusieron los hombres». Cit. en Vitoria, Francisco: Obras de Relecciones Teológicas. Ed. crítica del texto latino, versión española del P. Teófilo Undánoz, O. P. Madrid: Editorial Católica, 1960, pp. 183-185.

28. Vitoria, Francisco: "Art. tercero: si la razón de cualquiera puede establecer una ley", De Legibus. Salamanca: Eds. Universidad de Salamanca, 2010, p. 95. Véase la resonancia de las tesis tomistas.

29. Vitoria, Francisco: "Art. segundo: Si la ley ordena siempre al bien común", op. cit., p. 93.

30. Vitoria, Francisco, Sentencias. Selección del P. Getino. Barcelona: Eds. Fe,1939, p. 136. 
Queda claro que la «seguridad pública», que le preocupa mucho, no es en Vitoria un derecho humano, sino una obligación del poder, que dispone al efecto de la función legislativa y de la competencia punitiva. Sin embargo la potestad del Príncipe o de la autoridad establecida y aceptada por la comunidad no es ilimitada: Los derechos naturales del hombre la constriñen. Particularmente debe respetar la libertad de los súbditos («más útil que cualquier bien privado»31) y los derechos vinculados a la misma (libertad de comunicación, circulación y comercio) entre otros. No menciona entre ellos expresamente, al menos bajo tal denominación, un «derecho humano a la seguridad personal». Sin embargo defiende el derecho de toda persona a ser juzgada antes que condenada a muerte y se preocupa de la defensa de "derechos del reo" ${ }^{32}$, formulando varios de los tópicos que luego aparecerán en los teóricos del derecho a la seguridad jurídica en general o a la seguridad penal y procesal ${ }^{33}$. Así, mucho antes de que lo hiciera Beccaria en su Tratado de los Delitos y de las Penas, publicado en 1764, condena la tortura como método probatorio de delito o culpa y los castigos excesivamente crueles, pareciéndole lícito que el reo intente burlarlos e incumplir las sentencias injustas, o incluso las justas si está en riesgo su vida (al condenado a muerte siempre le es lícito huir y también al que es condenado a mutilaciones). Cabe destacar, como subraya Cláudio Brandão, que, además de establecer el vínculo necesario entre pena y culpa, defiende la posibilidad de derogar la ley penal si la costumbre ha establecido su inaplicación. En todo caso, concluye el profesor Brandão «el pensamiento de Vitoria, está en la matriz de la dogmática penal contemporánea, no por haber delineado las instituciones penales en sí mismas, sino por haber revelado su sustancia, su más esencial fundamento: la protección en el campo penal de la dignidad de la persona humana ${ }^{34}$.

Más de cien años después de que Vitoria subrayara la obligación del Monarca de respetar los derechos humanos y realizara pioneras incursiones en el campo del derecho de las personas a defenderse de un sistema penal injusto, Hobbes,

31. Hernández, Ramón: Derechos humanos en Francisco Vitoria. Antología. Salamanca: Ed. San Esteban, 1984, p. 136.

32. Brandão, Cláudio: «Las bases del Derecho Penal en Francisco Vitoria». En: Pando Ballesteros, Paz; Garrido Rodríguez, Pedro y Muñoz Ramírez, Alicia: El cincuentenario de los Pactos Internacionales de Derechos Humanos de la ONU. Libro Homenaje a la Profesora M. ${ }^{a}$ Esther Martínez Quinteiro. Salamanca: Eds. Universidad, 2018. p. 193, y del mismo "Francisco de Vitoria y la raíz del derecho penal", Revista de Direitos e Garantías Fundamentais, Faculdade de Direito de Vitória, v. 18, n. 1, 2017 (jan./ abr.), pp. 165-186, disponible en <http://sisbib.emnuvens.com.br/direitosegarantias/article/view/925> (C. 15-05-2017). El profesor Brandão señala en dicho artículo (p. 165) que «las ideas penales de Francisco de Vitoria ganan una notable importancia para la comprensión de la matriz del Derecho Penal de nuestros días, pues las mismas se vinculan al... iluminismo. Tales ideas rompen el paradigma del medioevo y sustituyen el teocentrismo por el antropocentrismo en el campo criminal».

33. Op. cit., p. 182.

34. Arbeláez Herrera, Ángela: «La Noción de Seguridad en Thomas Hobbes». Revista Facultad de Derecho y Ciencias Políticas, vol. 39, núm. 110, enero-junio, 2009, pp. 97-124. Ver también CossaRINI, P., OP. CIT 
M. ${ }^{a}$ ESTHER MARTÍNEZ QUINTEIRO

LA EXPANSIVIDAD DEL DISCURSO SOBRE EL "DERECHO HUMANO DE SEGURIDAD», UN «DERECHO SÍNTESIS». CONCRECIONES Y ETIOLOGÍA

primer filósofo, recuerda Ángela Arbeláez, que crea una teoría política basada en la seguridad ${ }^{35}$, considera ésta como objetivo prioritario, pero vuelve a confiarla al fortalecimiento de la potestad regia. Rodeado de terrores y tensiones con los poderosos, y muy pesimista sobre la naturaleza del ser humano, que consideraba cruel y egoísta, defendió en El Leviatán (1651) la pertinencia del pacto social que libraría a los hombres, lobos para sus congéneres, de la confrontación inevitable en el "estado de naturaleza", al precio de renunciar a sus derechos naturales y someterse al absolutismo de los reyes, a la postre obligados, pensaba, a proteger la vida y seguridad de los súbditos para asegurar su sumisión.

En realidad nadaba Hobbes a contracorriente, pues antes de que el Padre Vitoria hiciera en la Universidad de Salamanca su somera incursión en la defensa de la seguridad y de los derechos del reo, es fácilmente demostrable que la demanda de derechos de seguridad personal por los súbditos de los reyes había sido una de las reivindicaciones más clara y tempranamente formulada en diferentes países. En particular en Inglaterra, entre el siglo XIII y el XVII, o en sus colonias americanas, se hicieron concesiones conciliadoras a tales demandas en renombradas normativas arrancadas al Monarca, o dirigidas a favorecer el poblamiento colonial, y tradicionalmente consideradas antecedentes de los textos de derechos humanos, solo aparecidos en propiedad después, en la Edad Moderna (Carta Magna de Juan sin Tierra, de 1215, Petición de Derechos de 1628; Cuerpo de Libertades de la Babía de Massachusetts, de 1641; Normas fundamentales de Carolina de 1669-70; Concesiones y Acuerdos de West New Jersey, de 13 de marzo de 1677; Ley de Habeas Corpus, impuesta por la Cámara de los Comunes en 1679 y la Bill of Rights, de 1688, acatada por el rey Guillermo de Orange tras el derrocamiento de Jacobo II en la «Gloriosa Revolución» liberal).

Superando el fatalismo de Hobbes, y acomodándose con más pragmatismo a los nuevos tiempos, Locke, sostuvo en el Segundo Tratado sobre el Gobierno Civil $(1689)^{36}$, publicado un año después de la Bill of Rights de 1688, que la razón del pacto social, sobre el que se asienta el poder del Estado, era garantizar la seguridad de todos los ciudadanos, pues el hombre, en el "estado de naturaleza» (pese a gozar de los inalienables derechos naturales a la vida, la libertad y la propiedad y disponer del derecho a defenderlos frente posibles transgresores, castigándolos, en cuanto en dicho estado rige la Ley Natural que requiere su respeto) está, "sin embargo, expuesto constantemente a la incertidumbre» (dada la subjetividad inevitable de la interpretación individual de tal Ley y a la dificultad para castigar cada

35. Locke, John: Segundo Tratado sobre el Gobierno Civil Un ensayo acerca del verdadero origen, alcance y fines del Gobierno Civil. SALUS POPULI SUPREMA LEX ESTO. Madrid: Alianza Editorial, 2000. Disponible en <http://cinehistoria.com/locke_segundo_tratado_sobre_el_gobierno_civil.pdf> (C. 22-05-2017).

36. Puigpelat Martí, Francesca: "Libertad y seguridad en un nuevo contrato social», Anuario de Filosofía del Derecho Tomo XXII, 2005, p. 88 (Madrid: Ministerio de Justicia), en <https://www. boe.es/publicaciones/anuarios_derecho/abrir_pdf.php?id=ANU-F-2005-10008300112_ANUARIO_DE_ FILOSOF\%CDA_DEL_DERECHO_Libertad_y_seguridad_en_un_nuevo_contrato_social> (C. 25-05-2017). 
uno a sus infractores y a ser ecuánime en el castigo en cuanto afectado) y está expuesto asimismo «a la amenaza de ser invadido por otros» 37 . Pero precisamente por eso, porque lo que hoy denominaríamos "seguridad pública" es una de las irrenunciables funciones del que gobierna, y dada la tendencia del poder a abusar, hay que ponerle límites, dividiéndolo, mediante la separación del legislativo y el ejecutivo, no siendo exigible al hombre libre, para serlo, reconocer más poder que el consentido, o renunciar a actuar conforme a su voluntad en aquello que la ley no prohíbe, o conforme a sus derechos individuales naturales, que el Estado ha de respetar y que, de ser transgredidos, legitiman el derecho de resistencia a la opresión de los ciudadanos. La libertad individual y la seguridad, enfrentadas en Hobbes, obrando la segunda en detrimento de la primera, quedan salvaguardadas y son conciliables en Locke, defensor del "derecho natural a la seguridad jurídica", soporte del de la libertad y propiedad de toda persona.

Cuando Locke sostiene que ningún hombre puede ser detenido o retenido arbitrariamente, que no debe considerársele delincuente sin una ley penal que determine previamente el delito, que no procede que se le juzgue sin garantías y que tiene derecho a que se presuma su inocencia hasta que se demuestre lo contrario $^{38}$, sigue los pasos de los derechos concedidos a los ingleses libres por los textos declarativos o normativos que antes apuntamos, pero lo novedoso era que convertía en universales inalienables, no graciables, ni negociables, tales derechos, algo que no dejarían de recordar en breve, para legitimar su rebelión, los colonos americanos levantados contra el Reino de Gran Bretaña.

El derecho humano individual a la seguridad jurídica avanzado por los primeros defensores de los derechos humanos, que lleva aparejada la seguridad procesal y la penal, logrará afirmarse, completarse y positivarse a lo largo de la Guerra de la Independencia en Norteamérica, en la que aparecieron también formuladas otras dimensiones del derecho humano a la seguridad. La Declaración de Derechos del Buen Pueblo de Virginia, de 12 de junio de 1776, que después fue muy influyente en la Francia revolucionaria, suma a la proclamación del derecho «innato» de todo ser humano a su seguridad, incluida la vertiente procesal y penal de la misma, ${ }^{39}$ el derecho "del pueblo» (colectivo) a la «seguridad del pueblo, nación o comunidad»,

37. Eso no es incompatible con el derecho y el deber del poder de castigar a quien se sitúe fuera del pacto social atentando contra el derecho la vida, salud, libertad o propiedad de los demás, derecho que pasa de su detentador en el estado de naturaleza, el individuo, al Estado, precisamente en el mencionado pacto.

38. Menos influyente que la de Virginia, la Declaración de Derechos y Normas fundamentales de Delaware, de 11 de septiembre de 1776, reitera parecidos principios en materia de seguridad procesal y penal.

39. Pueden verse algunas teorías sobre los contenidos que unos y otros le atribuyen y sobre su manipulación por los estados fuertes en CARDinale, María Eugenia: «Seguridad Internacional y derechos humanos: una reflexión a partir de los aportes del cosmopolitismo crítico y el liberalismo ofensivo", Revista de Estudios en Seguridad Internacional (RESI), vol. 3, n. ${ }^{\circ}$ 1, 2017, pp. 127-148. DOI: <http:// dx.doi.org/10.18847/1.5.7>. 
M. ${ }^{a}$ ESTHER MARTÍNEZ QUINTEIRO

LA EXPANSIVIDAD DEL DISCURSO SOBRE EL "DERECHO HUMANO DE SEGURIDAD», UN «DERECHO SÍNTESIS». CONCRECIONES Y ETIOLOGÍA

lo que hoy llamaríamos "seguridad nacional» y "ciudadana». De la "seguridad del pueblo" se ocupa de nuevo la Declaración de Independencia de los Estados Unidos el 4 de julio de 1776, sin entrar en cambio en el derecho a la seguridad personal, pero las distintas manifestaciones de ésta pasan a ser incorporadas en 1791 muy detalladamente en la Constitución de 1787 mediante la incorporación de las 10 primeras enmiendas, la mayoría de las cuales se destinan precisamente a explicitar sus ya conocidas connotaciones.

Antes del estallido de la Revolución Francesa en 1789, Francia se hallaba bien preparada para redundar en la exigencia de seguridad individual, pues sus ilustrados no sólo habían leído detenidamente a Locke, entre muchos ilustrados de otros países, sino que habían acogido con particular entusiasmo la aparición de la obra del milanés Cesare de Beccaria, De los delitos y las penas, publicada en 1764, que acabó por desprestigiar el sistema penal del Antiguo Régimen y fortalecer el deseo de los galos de disfrutar de seguridad.

La Revolución Francesa ignoró, entre otras cosas, la condena de la pena de muerte por el ilustrado italiano, pero sus Declaraciones de Derechos del Hombre $y$ del Ciudadano, en particular la de 1789, constitucionalizada en 1791, y convertida en texto mítico de los derechos humanos con el paso del tiempo, si bien no resolvieron las ambigüedades conceptuales que permanecen sobre diferentes dimensiones del derecho humano a la seguridad, reforzaron los tópicos del derecho universal a la seguridad jurídica personal, tal como seguimos entendiéndolo hoy y avanzaron la necesidad no solo de respetarla, sino también de protegerla mediante la articulación de una acción positiva de defensa y prevención.

En efecto, en lo que concierne a lo que denominaríamos actualmente la "seguridad ciudadana" (la que garantiza el disfrute los derechos del ciudadano) -lastrada todavía hoy por un elevado grado de indefinición y por el mantenimiento de la polémica acerca de si debe ser concebida como un servicio público estatal obligado, o debe ser entendida como un derecho del ciudadano- el Artículo 12 de la Declaración de Derechos del Hombre y del Ciudadano de 1789 da por sentada la obligación de procurarla, encomendando a la fuerza pública su protección, pero sin etiquetarla ni resolver todas las dudas respecto a la naturaleza de tal obligación:

"La garantía de los derechos del hombre y del ciudadano -dice textualmente- necesita de una fuerza pública; por lo tanto, esta fuerza ha sido instituida en beneficio de todos, y no para el provecho particular de aquellos a quienes ha sido encomendada".

Por su parte, la Declaración de Derechos del Hombre y del Ciudadano de 1793, antes de proclamar, en los artículos 13, 14 y 15, el derecho a la seguridad personal, penal y procesal del individuo, hace aparecer (Artículo 2) la «seguridad", sin calificativos ni acotaciones, como uno de los derechos naturales e imprescriptibles del hombre, del mismo rango que la igualdad, la libertad y la propiedad, ofreciendo en su Artículo 8..$^{\circ}$ una definición amplia y anticipadora de la misma, que la convierte en un «derecho de prestación» inclusivo de todos los demás derechos, afirmando: 
M. ${ }^{a}$ ESTHER MARTÍNEZ QUINTEIRO

LA EXPANSIVIDAD DEL DISCURSO SOBRE EL "DERECHO HUMANO DE SEGURIDAD», UN «DERECHO SÍNTESIS». CONCRECIONES Y ETIOLOGÍA

«La seguridad consiste en la protección acordada por la sociedad a cada uno de sus miembros para la conservación de su persona, de sus derechos y de sus propiedades".

Había ya, al término de la Segunda Guerra Mundial, tras la amplia difusión de las elaboraciones apuntadas, y de su recepción y reelaboración como derechos ciudadanos en las constituciones liberales del siglo XIX y parte del xx, una tradición jurídica de la que echar mano para formular la irrenunciabilidad del derecho a la seguridad de todo ser humano y la obligación del Estado de respetar la libertad de la persona y su patrimonio, de "proteger» frente a terceros tales bienes jurídicos y de garantizar todos los demás derechos del ciudadano.

Los fundadores de las Naciones Unidas creían por otra parte, que, más allá de la función aseguradora de cada uno de sus Estados miembros, la ONU debía tener un papel al respecto: La Carta de la ONU, firmada el 26 de junio de 1945 en San Francisco, al terminar la Conferencia destinada a fundarla, en vigor desde el 24 de octubre de dicho año, se comprometía a unir las fuerzas de todos sus miembros para el mantenimiento de la paz y la «seguridad internacionales», confiriendo al Consejo de Seguridad -que ha resultado un fiasco- la responsabilidad primordial de mantenerlas. Su Artículo 55 estipulaba que para lograr tales propósitos la ONU debía promover niveles de vida más elevados, trabajo permanente para todos, y condiciones de progreso y desarrollo económico y social, solucionado los problemas internacionales de carácter económico, social y sanitario y otros problemas conexos, y procurando la cooperación internacional para elevar la cultura y mejorar la educación, así como para hacer posible el respeto universal a los derechos humanos y a las libertades fundamentales de todos, sin hacer distinción por motivos de raza, sexo, idioma o religión, y para garantizar la efectividad de tales derechos y libertades.

La concepción globalizadora y holística de la seguridad, apuntada en la Carta de San Francisco, subyace, aunque se diluya al punto que puede pasar desapercibida a un lector no atento, al texto de la Declaración Universal de 1948. No obstante sus redactores eran tan renuentes a arriesgarse a cuestionar la centralidad de los Estados soberanos en el juego de las relaciones internacionales que el único artículo de la DUDH, el 28, en que se proclama algo parecido al derecho a la "seguridad internacional", al que tampoco se llama por este nombre, se formula como un derecho subjetivo de indefinido sujeto pasivo, un tanto etéreo: «Toda persona [proclamaba el Artículo 28] tiene derecho a que se establezca un orden social e internacional en el que los derechos y libertades proclamados en esta Declaración se hagan plenamente efectivos». ¿Cuál será el "orden social e internacional» que asegure todos los derechos humanos? ¿Implicará recortes de la soberanía nacional? ¿Quién lo establecerá? ¿Cómo se garantiza a "toda persona» tal cosa? La ONU nunca ha explicado bien este texto, salvo que sea ella la que se esté ofreciendo como garante, y, en ese caso, nunca lo ha hecho bien.

Los autores de la Declaración de 1948 dejaban mucho más claro el alcance y entidad del secular "derecho a la seguridad personal», que la del más novedoso, difuso 

UN «DERECHO SÍNTESIS». CONCRECIONES Y ETIOLOGÍA

y polémico derecho a la "seguridad internacional», si podemos entender que tal es efectivamente, al margen de su denominación, el proclamado en el Artículo $28^{40}$, esforzándose en perfilar, detallar y completar las implicaciones jurídicas, procesales y penales de la misma (tutela judicial efectiva, Art. 8; presunción de inocencia, juicio justo, tipificación del delito, Arts. 10, 11, y 16; derecho a la nacionalidad, Art. 15). De lo que ni siquiera se preocuparon fue de formular la exigibilidad de la «seguridad pública» o la "seguridad ciudadana», de definir a quién compete garantizarla, o de precisar, en su caso, tal vez por ser este concebido cómo asunto un interno de los Estados, cómo había de entenderse un hipotético derecho humano enmarcable en tal rótulo, lo con el tiempo se convertirá en un desafío para los organismos de derechos humanos que considerarían tal precisión muy necesaria para orientar las políticas públicas nacionales de seguridad en un sentido democrático ${ }^{41}$. Para algunos cabría deducir tal "derecho humano" del modo general e imperativo en que se declara la existencia del "derecho a la seguridad» (Art. 3), pero eso no deja de ser discutible.

Al margen de lo que el olvido antedicho pudiera implicar en diversos órdenes, por mucho tiempo, hasta que empezó a ser considerada como derecho consuetudinario de obligado cumplimiento, la Declaración Universal de 1948 fue entendida como no vinculante, por lo que tampoco podía esperarse que bastara precisar bien en ella los contenidos de la seguridad personal en sus varias vertientes, física y jurídica, así como la universalidad del principio, para evitar que fuera transgredido en los estados autoritarios, y reducido, en algunos otros, teóricamente democráticos, a la condición, restrictiva, de derecho fundamental de sus ciudadanos, no extrapolable a extranjeros; de ahí la importancia de la inclusión, esperable, del derecho individual universal a la seguridad de las personas en el Pacto Internacional de los Derechos Civiles y Políticos, de 1966 (Arts. 9 al 17 del PIDCP), que obligaba

40. De tal carencia se hace eco, por ejemplo, el Informe sobre seguridad ciudadana y derechos bumanos elaborado por la Comisión Interamericana de Derechos Humanos (CIDH). (OEA/Ser.L/V/II. Doc. 57.31 diciembre 2009) en el marco de un acuerdo entre la CIDH, el Fondo de las Naciones Unidas para la Infancia (UNICEF) y la Oficina de la Alta Comisionada de las Naciones Unidas para los derechos humanos (OACNUDH), un organismo nacido en 1993, presidido entre 2008 y 2014 por la jurista sudafricana Navanethem Pillay, muy implicada en cuestiones de seguridad. Está disponible en <https:// www.cidh.oas.org/pdf\%20files/SEGURIDAD\%20CIUDADANA\%202009\%20ESP.pdf> (C. 3-05-2017). El Informe reconoce que "el derecho internacional de los derechos bumanos no define en forma expresa el derecho a la seguridad frente al delito o a la violencia interpersonal o social, cuya prevención y control es el objetivo de las políticas sobre seguridad ciudadana, [pero entiende que] los Estados se encuentran obligados por un plexo normativo que exige la garantía de derechos particularmente afectados por conductas violentas o delictivas: el derecho a la vida; el derecho a la integridad física; el derecho a la libertad personal; el derecho a las garantías procesales y el derecho al uso pacífico de los bienes. Las obligaciones de los Estados miembros respecto a la seguridad ciudadana también comprometen el derecho a las garantías procesales y a la protección judicial; el derecho a la privacidad y a la protección de la honra y la dignidad; el derecho a la libertad de expresión; el derecho a la libertad de reunión y asociación; y el derecho a la participación en los asuntos de interés público. En un sentido amplio, la seguridad ciudadana también puede incorporar medidas de garantía de los derechos a la educación, la salud, la seguridad social y al trabajo, entre otros» (op. cit., p. 8).

41. Ver nota 40 . 
al menos a sus ratificantes a respetarla, y también de que se lograra la aprobación y ratificación de Convenios varios, entre ellos los capaces de comprometer a los Estados-Parte de los mismos a garantizar que harían todo lo posible para que no se esclavizara a nadie, se evitara la trata de personas (prácticas explícitamente prohibidas en el Art.4 de la Declaración Universal) y se lograra que no se torturara a persona alguna, ni se la sometiera a penas y tratos crueles, inhumanos y degradantes (prácticas vedadas por el Art. 5 de la Declaración).

El conjunto normativo de instrumentos internacionales articulado por la ONU con los fines antedichos desarrolla con precisión satisfactoria, desde el punto de vista teórico, los componentes "negativos" del derecho a la seguridad personal (los que obligan al Estado a no transgredir y a respetar), tal como acabamos de ver, pero resulta menos satisfactoria, por su indefinición o inexistencia en unos $\operatorname{casos}^{42}$, y por su debilitante posibilismo en otros, la forma en que son tratados los «derechos de prestación", incluidos los "derechos de segunda generación", tan necesarios como los primeros para que las personas vean garantizada, además de su seguridad física, y la de su patrimonio, la de "todos» sus derechos y libertades fundamentales, que, a tenor del Preámbulo de la Declaración Universal, y antes de que las modernas teorías del desarrollo empezaran a vehicular el concepto integral de "seguridad humana", sobre el que volveremos más adelante, debieran entenderse como una parte irrenunciable del "derecho humano de seguridad", tomado en su globalidad y sin acotaciones específicas ${ }^{43}$.

Aunque a regañadientes por parte de algunos, y no sin polémica, los redactores del texto de la DUDH, que hoy se entiende de obligado cumplimiento para todos los Estados-Miembros de la ONU, incluyeron en ella la lista de los derechos sociales, económicos y culturales que consideraron necesarios para cumplir con la proclamada- en el Preámbulo de la Declaración- como «aspiración más elevada del hombre»: el advenimiento de un mundo donde los seres humanos, estuvieran

42. Uno de los "considerandos" del Preámbulo de la Declaración Universal de los Derechos Humanos de 1948 es, en efecto, que «los Estados Miembros se han comprometido a asegurar, en cooperación con la Organización de las Naciones Unidas, el respeto universal y efectivo a los derechos y libertades fundamentales del hombre y que una concepción común de estos derechos y libertades es de la mayor importancia para el pleno cumplimiento de dicho compromiso". De ahí se desprende que, en el plano del "discurso propositivo" de la ONU, el "derecho humano a la seguridad" era, pues concebido, ya en 1948, como un derecho inclusivo de la totalidad de los derechos humanos.

43. Ciertamente, dicho principio había sido utilizado en 1948 en la Declaración Universal de Derechos Humanos con carácter general, tanto para los derechos sociales como para los civiles y políticos, cuando la aplicación de la DUDH dependía del voluntarismo de los Estados-Miembro de la ONU, al no haber sido consensuada como un documento vinculante, sino meramente proclamada como «ideal común por el que todos los pueblos y naciones deben esforzarse, a fin de que tanto los individuos como las instituciones, inspirándose constantemente en ella, promuevan, mediante la enseñanza y la educación, el respeto a estos derechos y libertades, y aseguren, por medidas progresivas de carácter nacional e internacional, su reconocimiento y aplicación universales y efectivos...». Esta "progresividad" dependía de la voluntad de las Partes y no de sus posibilidades materiales, que, de existir, en el caso del PIDESC, se erigen en un mandato imperativo... salvo para los países en desarrollo (lo que les resta universalidad). 
M. ${ }^{a}$ ESTHER MARTÍNEZ QUINTEIRO

LA EXPANSIVIDAD DEL DISCURSO SOBRE EL "DERECHO HUMANO DE SEGURIDAD», UN «DERECHO SÍNTESIS». CONCRECIONES Y ETIOLOGÍA

"liberados del temor y de la miseria». Sin embargo, el Artículo 22 de la Declaración condicionaba su obligatoriedad "a la organización y recursos disponibles de cada Estado", como es bien conocido:

"Toda persona, como miembro de la sociedad [dice literalmente el Artículo citado] tiene derecho... a obtener, mediante el esfuerzo nacional y la cooperación internacional, habida cuenta de la organización y los recursos de cada Estado, la satisfacción de los derechos económicos, sociales y culturales, indispensables a su dignidad y al libre desarrollo de su personalidad».

Esta deficiente imperatividad primigenia de los derechos de segunda generación proclamados por la DUDH, que ha legitimado mucho descompromiso y ha hecho correr mucha tinta, fue sólo relativamente corregida en diversos Tratados y Convenios que desarrollaron posteriormente dichos derechos (vinculantes únicamente para los países que quisieron ratificarlos), siendo el Pacto Internacional de Derechos Económicos, Sociales y Culturales (PIDESC, aprobado en 1966, y vigente desde 1976), el más importante a dichos efectos por el elevado número de EstadosParte que lo han ratificado (166 de los 193 de la ONU en 2017) y por componer, con la Declaración Universal, el PICP, y los Protocolos facultativos anexos, la Carta de Derechos Humanos de la ONU.

El PIDESC establece:

Artículo 2.1. Cada uno de los Estados Partes en el presente Pacto se compromete a adoptar medidas, tanto por separado como mediante la asistencia y la cooperación internacionales, especialmente económicas y técnicas, hasta el máximo de los recursos de que disponga, para lograr progresivamente por todos los medios apropiados, inclusive en particular la adopción de medidas legislativas, la plena efectividad de los derechos aquí reconocidos.

2.3: Los países en desarrollo, teniendo debidamente en cuenta los derechos humanos y su economía nacional, podrán determinar en qué medida garantizarán los derechos económicos reconocidos en el presente Pacto a personas que no sean nacionales suyos".

Para algunos autores el principio de "progresividad", aunque introducido para exigir que se vaya llegando en cada momento en cuestión de cumplimiento de los derechos de segunda generación al máximo permitido por los recursos disponibles (limitación que no es más que una concesión al principio de realidad y que significa un avance con respecto a la DUDH), relativiza la obligación de la implementación de aquellos derechos sociales, económicos o culturales que el Estado-Parte del PIDESC alegue (ante el Comité de 18 expertos internacionales independientes encargado de vigilar la implementación del Pacto) que le resultan económicamente inasequibles, facilitando de facto su dilación ad calendas graecas, sin costo de su buena imagen, en caso de falta de voluntad ${ }^{44}$. Por otra parte

44. La categoría está mal definida y permite apreciaciones muy diferentes de qué países deben considerarse tales. El Listado de países en vías de desarrollo, elaborado por la Agencia de Marketing 
M. ${ }^{a}$ ESTHER MARTÍNEZ QUINTEIRO

LA EXPANSIVIDAD DEL DISCURSO SOBRE EL "DERECHO HUMANO DE SEGURIDAD», UN «DERECHO SÍNTESIS». CONCRECIONES Y ETIOLOGÍA

la moratoria concedida a los muy numerosos, y no rigurosamente encasillables, "países en desarrollo» ${ }^{45}$, en tanto lo fueran, permitiéndoles no reconocer los derechos de segunda generación a quienes, aun residiendo en ellos, no tuvieran la condición de "nacionales» del país, les resta universalidad, e impide, precisamente por eso, que puedan considerase derechos humanos stricto sensu.

Si la ONU, a la que no cabe negarle laudables esfuerzos y logros nada despreciables, entre ellos la creación, por consenso, del Derecho Público Internacional de los Derechos Humanos, hubiera conseguido que las funcionalmente muy insatisfactorias instituciones de crédito del sistema de las Naciones Unidas, y las actuaciones de su Asamblea General, de su Consejo Económico y Social (ECOSOC) y de sus organismos especializados en el fomento del desarrollo, así como su Programa para el Desarrollo (PNUD), creado en 1965 y que actúa hoy sobre cerca de 170 países, administrando el Fondo de las Naciones Unidas para el Desarrollo de la Capitalización (FNUDC), aseguraran una cooperación internacional completamente despolitizada, verdaderamente solidaria y capaz con sus aportes de hacer realidad los derechos de segunda generación allí donde los Estados no tuvieran recursos a tal fin, o al menos hubiera conseguido erradicar la pobreza extrema, que afecta a la cuarta parte de la población mundial, el posibilismo del discurso propositivo y normativo dirigido a promoverlos, hasta aquí apuntado, hubiera tenido una trascendencia menor. Pero no es el caso. Si la ONU, en suma, dispusiera de unas estructuras adecuadas para dar contenidos al «derecho al orden social e internacional" congruente con los derechos humanos en ella consensuados, lo de menos sería la ambigüedad del Artículo 28.

Sin embargo, la ONU, organismo impulsor de la democracia poco democrático, no es capaz de generar la «seguridad» debida, que es su razón de ser última, porque es un gigante de pies de barro, con presupuestos insuficientes para cumplir su ingente tarea, servida por una burocracia a veces inoperante y a veces corrupta, con un Consejo de Seguridad anacrónico y paralizado por el derecho a veto de sus miembros permanentes, siempre enfrentados, lo que impide que actúe eficazmente para solucionar conflictos o evitar masacres, con un Alto Comisionado

Online y Diseño web, disponible en <https://www.internacionalweb.com/paises-en-vias-de-desarrollo> (C. 10-12-2017) incluye a: Níger, Sierra Leona, Malí, Burkina Faso, Guinea-Bissau, Rep. Centroafricana, Chad, Etiopía, Burundi, Mozambique, Congo, Malawi, Zambia, Costa de Marfil, Benin, Tanzania, Angola, Guinea, Nigeria, Ruanda, Eritrea, Senegal, Gambia, Haití, Mauritania, Kenya, Zimbabwe, Lesotho, Djibuti, Togo, Swazilandia, Uganda, Camerún, Madagascar, Timor-Leste, Sudán, Congo, Papúa-Nueva Guine, Nepal, Blangadesh, Ghana, Bután, Pakistán, Laos, Comoras, Botswana, Myanmar, Camboya, Islas Salomón, Santo Tomé y Príncipe, India, Namibia, Gabón, Tayikistán, Sudáfrica, Guinea Ecuatorial, Vanuatu, Guatemala, Honduras, Mongolia, Bolivia, Moldavia, Uzbekistán, Nicaragua, Egipto, Kirguizistán, Vietnam, Indonesia, Siria, Cabo Verde, Turkmenistán, Jamaica, Guyana, Argelia, El Salvador, Territorios Ocupados Palestinos, Azerbaiyán, Maldivas, Georgia, Rep. Dominicana, Sri. Lanka, Paraguay, Suriname, Jordania, Ecuador, Perú, Armenia, Kazajstán, Líbano, Ucrania, Albania, Venezuela, Colombia, Brasil.

45. ONU, Crecimiento de Número de Estados Miembros de las Naciones Unidas, desde 1945 al presente, en <http://www.un.org/es/sections/member-states/growth-united-nations-membership1945-present/index.html> (C. 13-08-2017). 
de Derechos Humanos políticamente impotente y con un inoperante Consejo de Derechos Humanos (que en 2006 sustituyó en vano a la politizada Comisión de Derechos Humanos, creada en 1947) destinado teóricamente a velar por los mismos, pero participado por Estados que no creen en ellos y que se infiltran en el Consejo, ya para evitar ser denunciados por sus incumplimientos, ya para bloquear la implementación de derechos que no comparten.

Se añaden a todos estos considerandos las dificultades innegables de la ONU para adaptarse a un mundo cambiante, especialmente a partir de la caída del Muro de Berlín en 1989 y del fin del sistema bipolar, para generar consensos entre un cada vez más elevado número de Estados-miembro económica y culturalmente muy desiguales, con intereses contrapuestos (se pasa de 51 Estados en 1945 a 58 miembros en 1948, 80 en 1956, 122 en 1966, 159 en 1990, y 189 en el 2000. En 2011, después de la entrada de Sudán del Sur, los estados-miembros eran ya los 193 presentes aún en 201746) y para evitar su confrontación, o sustraerse a las manipulaciones y presiones de los países más ricos, de los que depende la mayor parte de su financiación ${ }^{47}$. Todos estos factores coadyuvan a la alarmante crisis

46. La cota devengada a la ONU por cada país y sus contribuciones a las operaciones de paz dependen de su riqueza relativa. En 2014 cuatro países aportaban la mitad de su financiación: EE. UU., Japón, Alemania y Rusia. Algunos países con recursos utilizan aportaciones especiales o donaciones puntuales para centros u operaciones determinadas con el fin de asegurar su influencia o evitar denuncias o ataques por conductas antidemocráticas, desestabilizadoras o contrarias a los derechos humanos, o para asegurarse un puesto en los organismos de la ONU.

Las relaciones ambivalentes de EE. UU. y la ONU, muy dependiente de su financiación, son bien conocidas, como subrayan en 2005 Giraldo LóPEZ, Lina y MiLANESE, Juan Pablo: EEUU-ONU: Una relación patológica de poder, en <https://repository.icesi.edu.co/biblioteca_digital/bitstream/10906/82178/1/ milanese_relacion_patologica_2005.pdf> (C. 1-11-2017). Véase también KenN, Soeren: La reforma de la ONU y los intereses nacionales de Estados Unidos, EEUU y el Diálogo Transatlántico / Organismos Internacionales- ARI N. ${ }^{\circ}$ 200/2004.

Recordaremos para ilustrar la persistencia y actualidad de esta problemática que el presidente de Estados Unidos amenazó el 20 de diciembre de 2017 con retirar las contribuciones económicas a los países que respaldasen una resolución de la ONU que condenaba su decisión de reconocer oficialmente a Jerusalén como capital de Israel [según informaba Nicolás Alonso en el artículo «Trump amenaza a los países de la ONU con retirar ayudas si critican su reconocimiento de Jerusalén", publicado en el periódico El País del 21 de diciembre de 2017, disponible en <https:// elpais.com/internacional/2017/12/20/ estados_unidos /1513796002_536422.html> (C. 21-12-2017)]. Cuando 128 países votaron el 21 de diciembre contra Trump, este afirmó, furioso, "que la ONU no estaba a la altura de su potencial, y en lugar de resolver problemas 'los causa”. [Mundo Hispánico, Agencia EFE, disponible en <https://mundohispanico.com/noticias/trump-ataca-a-la-onu-y-dice-que-en-lugar-de-resolver-problemas-los-causa> (C. $21-12-2017)]$.

El 26 de diciembre la Agencia EFE informaba: «La misión estadounidense en las Naciones Unidas acordó una reducción de más de 285 millones de dólares, alegando «ineficiencia y gastos excesivos» del organismo internacional. Además, reducirán las funciones administrativas y de apoyo». [EFE: «El gobierno de Trump aplica un fuerte recorte al presupuesto que asigna a la ONU», Univisión, 26-12-2017. Disponible en <https://www.univision.com/noticias/politica/el-gobierno-de-trump-aplica-un-fuerterecorte-al-presupuesto-que-asigna-a-la-onu> (C. 27-12-2017)].

47. Sobre los primeros intentos véase Boutros-GHali, Boutros: «Un programa de paz», FASOC, vol. VIII, n. ${ }^{\circ} 1$ (Versión resumida extractada del Boletín Micronoticias preparado por los Servicios de 

UN «DERECHO SÍNTESIS». CONCRECIONES Y ETIOLOGÍA

de legitimidad de las Naciones Unidas, que, tras los modestos retoques de 1963, ampliando el número de miembros del Consejo de Seguridad y del ECOSOC y, de nuevo los de este último en 1971, se estanca y atraviesa grandes dificultades financieras que merman su eficacia, enfrentándose desde hace cuatro décadas aproximadamente, como resultado de su incapacidad para readaptarse, a grandes críticas y crecientes demandas de transformación ${ }^{48}$. Los primeros intentos de impulsar cambios dirigidos a recuperar prestigio para la ONU, reforzando sus funciones en materia de paz y seguridad y agilizando su gestión fueron efectuados por el secretario general de la ONU entre 1992-1996, Butros Ghali. El mandatario egipcio logró que se hicieran algunas reformas estructurales menores, pero no las más trascendentes y demandadas, como la democratización y desbloqueo del Consejo de Seguridad, máximo órgano ejecutivo de la ONU, y la despolitización de la Comisión de Derechos Humanos, objeto de un sinnúmero de críticas por las manipulaciones de que era objeto. Para acallar el malestar que ambas cuestiones estaban generando crearía, el 20 de diciembre de 1993, un Grupo de Trabajo para estudiar la revisión de la Composición del Consejo de Seguridad, que no concluiría en modificación alguna hasta hoy, y promovería la creación del cargo de Alto

Información de las Naciones Unidas en Santiago, CEPAL. 6 de julio 1992, disponible en <http://www. ceppacr.org/3_un_programa_de_paz.pdf> (C. 11-11-2017) y FisAs ARMENGOL, Vicenç: El desafío de Naciones Unidas ante el mundo en crisis: la reforma de las Naciones Unidas y el futuro de los cascos azules. Barcelona: Icaria, 1994; sobre los esfuerzos realizados al efecto por el emblemático y carismático Koffi Annam, pueden verse entre otros: Bux, Hans: La reforma de las Naciones Unidas y las perspectivas futuras para el desarme. México: CISAN, 2006 y VALDÉs-Ugalde, José Luis y $\bigotimes$ CASCANTE, Jéssica: El multilateralismo, la reforma de la ONU y los desafíos del siglo XXI. Madrid: UNAM, 2007. Se puede consultar también la biografía de Kofi Annam, MousavizadeH, Nader: Intervenciones. Una vida en la Guerra y en la Paz, Madrid, Taurus, 2013, para conocer su discurso. Sobre la etapa de Ban Ki Moon, puede verse la biografía de Aldridge, Rebecca: Ban Ki Moon. United States: Chelsea House, 2014, y The future of the United Nations under Ban Ki-Moon. United States: Congress. House. Committee on Foreign Affairs, 2007; así como, Plate Plate, Tom: Conversations with Ban Ki-Moon: What the United Nations is Really Like: the View from the Top. Singapore: Marshall Cavendish Editions, 2012.

48. He aquí el balance de esta iniciativa realizado por El País el 21 de junio de 2014 en un artículo publicado por Javier el Hage en dicho periódico, con el título: "Despotismo ilustrado en la ONU: El príncipe de los derechos humanos", en <https://elpais.com/internacional/2014/06/21/actualidad/1403352174_208742.html> (C. 10-08-2017):

"La Oficina del Alto Comisionado para los Derechos Humanos (OACDH) fue creada mediante la resolución 48/141, aprobada por la Asamblea General el 20 de diciembre de 1993. Entre las funciones confiadas a la OACDH están: 1) asegurar el respeto de todos los derechos humanos; 2) prevenir casos de violaciones de derechos humanos; 3) promover la cooperación internacional para proteger los derechos humanos; 4) coordinar actividades relacionadas con el respeto y la promoción de los derechos humanos en la ONU; y 5) fortalecer y hacer más eficiente el respeto por los derechos humanos en el concierto de naciones de la ONU.

Sin embargo, hasta ahora las acciones del Alto Comisionado han sido en el mejor de los casos tímidas, por lo general carentes de norte democrático y a veces incluso reñidas con los ideales que persigue. Esto se debe a que la OACDH sufre, aunque en menor medida, del mismo problema estructural que padecen otros órganos de la ONU como el Consejo de Seguridad y el Consejo de Derechos Humanos, cuyos pronunciamientos y acciones concretas están altamente influenciados por dictaduras con poder de veto y membresía mayoritaria». 
M. ${ }^{a}$ ESTHER MARTÍNEZ QUINTEIRO

LA EXPANSIVIDAD DEL DISCURSO SOBRE EL "DERECHO HUMANO DE SEGURIDAD», UN «DERECHO SÍNTESIS». CONCRECIONES Y ETIOLOGÍA

Comisionado de Derechos Humanos, a la postre poco efectivo, por falta precisamente de independencia ${ }^{49}$. En contrapartida, presentó un Programa de Paz, en 1992, y un Programa de Desarrollo, en 1994, en los que se relaciona la paz, la democracia y los derechos humanos y se compromete a impulsarlos conjuntamente.

Entre 1997 y 2006 ocupa la secretaría, con el crucial beneplácito de los EE. UU., el carismático ghanés Kofi Annan, un gestor brillante, deseoso de reformar la ONU para fortalecerla, adecuándola a las nuevas relaciones de poder internacionales, que reiteró la trascendencia legitimadora y la interdependencia de las causas del desarrollo, la seguridad y los derechos humanos y la conveniencia de implicar a la sociedad civil, el sector privado, las ONG y las transnacionales en la generación de recursos y nuevos instrumentos para su defensa. El mismo año de su llegada a la Secretaría General planteaba un Programa de Reforma y Renovación de las Naciones Unidas comenzando por racionalizar su administración, simplificar la burocracia, reducir el gasto y procurar transparencia contable de la secretaría general, reforzando a cambio el liderazgo y prestigio de su Secretario. Para lograrlo, no solo debería funcionar mejor administrativamente el aparato burocrático sino que había que convencer a la comunidad internacional de la utilidad de la Organización, prestándole servicios que compensaran su costoso mantenimiento y las limitaciones inevitables de su capacidad decisoria impuestas por el multilateralismo a los Estados-parte en su política exterior. Estos límites, pensaba Annam, se harían más llevaderos en medida en que los Estados sintieran que eran escuchados en la ONU y que tenían un papel que desempeñar, al menos, de acuerdo con su peso real en el mundo.

En el año 2000 el Secretario General pondría en marcha la Declaración del Milenio, e impulsaría la fijación de los Objetivos del Milenio, involucrando en la operación a 147 Jefes de Estado y de Gobierno, reunidos en la Sede de las Naciones Unidas en Nueva York del 6 al 8 de septiembre de 2000, los cuales se comprometieron, entre otras cosas, "a aumentar la eficacia de las Naciones Unidas en el mantenimiento de la paz y de la seguridad, dotando a la Organización de los recursos y los instrumentos que necesitan en sus tareas de prevención de conflictos, resolución pacífica de controversias, mantenimiento de la paz, consolidación de la paz y reconstrucción después de los $\operatorname{conflictos}^{50}$, con el fin declarado, favorable para la imagen pública de los implicados y la mejora de su autoestima, de «liberar a hombres, mujeres y niños, de las condiciones abyectas y deshumanizadoras de la pobreza extrema, a la que en la actualidad están sometidos más de 1.000 millones de seres humanos..., hacer realidad para todos ellos el derecho al desarrollo y a poner a toda la especie humana al abrigo de la necesidad».

49. Resolución aprobada por la Asamblea General.55/2. Declaración del Milenio, disponible en <http://www.un.org/spanish/milenio/ares552s.htm> (C. 12-11-2017).

50. «Galardón: La ONU y Kofi Annan reciben el Premio Nobel de la Paz. El fallo reconoce su trabajo a favor de un mundo mejor organizado y más pacífico». El País, 12 de octubre de 2001, disponible en <https://elpais.com/internacional/2001/10/12/actualidad/1002837609_850215.html> (C.5 -08-2017). 
M. ${ }^{a}$ ESTHER MARTÍNEZ QUINTEIRO

LA EXPANSIVIDAD DEL DISCURSO SOBRE EL "DERECHO HUMANO DE SEGURIDAD», UN «DERECHO SÍNTESIS». CONCRECIONES Y ETIOLOGÍA

En 2001 el Premio Nobel de la Paz recayó «a partes iguales en las Naciones Unidas y en su secretario general... por su trabajo en favor de un mundo mejor organizado y más pacífico». El Comité subrayó que, en el centenario del Nobel, deseaba "proclamar que la única vía negociable hacia la paz y la cooperación global debe seguirse junto a las Naciones Unidas» 51 .

En los años inmediatos Kofi Annan intentó promover reformas estructurales de los diferentes órganos y agencias especializadas de la ONU, muy desfasados, no tanto para democratizarlos, como querían los países del Tercer Mundo, cuanto para hacerlos más incluyentes de la diversidad étnica y geográfica, introduciendo en ellos una representación equitativa de todos los continentes, tratando de evitar así la recurrente acusación de occidentalismo lanzada contra la Organización. También pretendió lograr que sus órganos y organismos se acomodaran a los cambios operados en las relaciones de poder mundiales, a fin de que las potencias emergentes tuvieran más presencia y voz en ellos y aceptaran decidir su acción exterior en el seno de la ONU, abandonando la tentación o pretensión de actuar de modo unilateral, riesgo deducible de los términos de la Estrategia de Seguridad Nacional de los Estados Unidos de América, publicada en septiembre de 2002, que recogía la doctrina Bush sobre la necesidad de la "guerra preventiva" contra los terroristas o los Estados dispuestos a dotarse de armas de destrucción masiva, y el anuncio de que los EE. UU. no dudarían en "actuar solos», si fuera preciso, para defenderse anticipadamente de ellos, lo que desempoderaría a las Naciones Unidas.

El Informe, un mundo más seguro: la responsabilidad que compartimos ${ }^{52}$, (elaborado por un Grupo de dieciséis expertos independientes designados por él, que fue presentado en 2004, y que fue seguido, en marzo de 2005, del Informe del Plan de Seguimiento de los Resultados de la Cumbre del Milenio, en la misma onda) ofrecía «una nueva visión de la seguridad colectiva e identificaba como amenazas y peligros a la paz y seguridad internacionales diversas situaciones presentes en el mundo, como la pobreza, las enfermedades infecciosas, el deterioro del medio ambiente, los conflictos internos y el terrorismo, la delincuencia internacional organizada o la proliferación de armas de destrucción masiva", sosteniendo que no se podrían afrontar estos riesgos si no se adoptaban «reformas estructurales en los órganos decisorios para ganar en efectividad, credibilidad y legitimidad „53. Recordaba que la seguridad internacional exige «libertad para vivir sin temor» $\mathrm{y}$ «libertad para vivir en dignidad», lo que requiere asegurar la protección de los derechos humanos de las personas.

51. Bermejo García, Romualdo y López-Jacoiste Díaz, Eugenia: «Un mundo más seguro: la responsabilidad que compartimos, Informe del Grupo de Alto Nivel sobre las menazas, el desafío y el cambio, a modo de introducción", Unisci Discussion Papers, n. ${ }^{\circ}$ 10, 2006 (enero), pp.1-20, en <https://dadun. unav.edu/bitstream/10171/23563/1/ADI_XXI_2005_01.pdf> (C. 10-08-2017).

52. Idem, p. 16.

53. «El Consejo de Seguridad - decía literalmente el Informe Un concepto más amplio de libertad-debe ser ampliamente representativo de las realidades del poder en el mundo actual". 
En lo que concierne a la reforma estructural propuesta por Kofi Annam, destaca la del Consejo de Seguridad, encargado de garantizar la «seguridad internacional", que había sido pensado para un mundo bipolar, desaparecido tras el fin de la Guerra Fría. El ghanés pretendía aumentar su reducido número de miembros, apenas 15 desde 1967 (5 permanentes, con veto, Estados Unidos, Reino Unido, República Francesa, Federación Rusa y República Popular China, y 10 rotativos), para dar cabida a algunos Estados que deseaban incrementar su presencia en los órganos de poder de la ONU, premiando su mayor contribución financiera, militar y diplomática, con el argumento de que eso lo convertiría en un espacio de diálogo más eficaz que hasta el momento, sin tocar el veto de los Estados que disponían de él, para evitar su resistencia ${ }^{54}$. Quería que el El Consejo Económico y Social (ECOSOC) se esforzara en generar desarrollo, incentivar a los países en desarrollo (a los que pretendía dar más presencia en el Banco Mundial y el FMI) y en captar recursos y fondos privados para promover el desarrollo. Pretendía sustituir el Comité de Derechos Humanos, de 57 miembros, acusado de servir a los intereses estratégicos de Rusia, China y los países arabo-islámicos, por un Consejo de Derechos Humanos, intergubernamental y permanente, más reducido que el Comité, con miembros comprobadamente comprometidos con los derechos humanos, a los que encargaba fiscalizar su cumplimiento, asegurándose así de que cumpliría su misión de promoción y protección de tales derechos en el mundo. Solo logró esto último, y, a la larga, la evolución del nuevo Consejo de Derechos Humanos, creado en 2006, no fue la esperada: su repolitización se reproduciría con el tiempo.

La figura de Kofi Annam ha suscitado odios y admiraciones contrapuestas por su gestión al frente de la ONU. "Hay críticos recalcitrantes [advertía en 2006 el periódico español El País] que han despreciado a Kofi Annan porque creen que tiene las manos manchadas de sangre ruandesa. Su desdén no ha disminuido con los años. Se opusieron a su segundo mandato como secretario general, a la concesión del Premio Nobel de la Paz, y han venido exigiendo continuamente su dimisión„55.

Las asociaciones de juristas americanistas (AAJ), unidas a las de Centro Europa-Tercer Mundo (CETIM), de orientación izquierdista, salieron en tromba para acusarlo de tratar de reforzar el dominio de la ONU por las grandes potencias y sobre todo por EEUU ${ }^{56}$, pese a que finalmente estos (que lo habían impuesto, tras vetar a Butros Gali, por no plegarse a su control) acabarían por distanciarse de su candidato a causa de su oposición a la intervención estadounidense en la Guerra

54. MeISTER, Stanley: "Kofi Annan, de Ruanda a Irak. Una biografía analiza los errores y aciertos del secretario general de Naciones Unidas». El País, 5 de noviembre de 2006.

55. CETIM y AAJ: Reformas en las Naciones Unidas. Críticas y propuestas de La AAJ y la CETIM, junio de 2005. <http://www.cetim.ch/legacy/es/documents/05-reforma_onu-cetim-aaj.pdf> (C. 3-08-2017).

56. Meyssan,Thierry: «Koffi Annan, piel negra, máscaras blancas». Damasco (Siria): Red Voltaire, 29 mar. 2012, en <http://www.voltairenet.org/article173348.html> (C. 5-08-2017). Thierry Meysan es un político y periodista francés, que entre 1995 y 2008 dirigió el Partido Radical de Izquierda galo, y que dirige la controvertida "Red Voltaire por la Libertad de Expresión". 
de Irak. En 2012 la Red francesa Voltaire por la Libertad de Expresión-especializada en el periodismo de investigación, muy crítica, anticlerical, antiestadounidense y, según sus críticos, antisemita-lo acusó de entregar la ONU a los intereses privados, así como de utilizar un discurso adormecedor y de servir subrepticiamente a la CIA, bajo capa de neutralidad, adaptando la ONU a la realidad de un mundo unipolar hegemonizado por los EE. UU., "tranquilizando las conciencias con unos cuantos programas altamente publicitados por los medios de comunicación para mantener las injusticias de carácter estructural, 57 .

La Reforma estructural profunda que necesitaba la ONU, y en particular el Consejo de Seguridad, seguía pendiente cuando se produjo la salida de Kofi Annan ${ }^{58}$, debiendo su sucesor, Ban-Ki-Mon (2007-2016), enfrentarse a la crecida de las demandas de cambio. Lo hizo sin demasiada energía y con poco éxito. Tuvo que habérselas, poco después de la salida de su predecesor, con 93 propuestas de reforma elevadas al Consejo de Seguridad, por 136 Estados miembros, de las que solo se aprobaron 5,4 de forma parcial. El coreano, que recibiría por su inacción el apodo de "el hombre invisible», acabaría despedido en medio de fuertes críticas ${ }^{59}$, viéndose por ello obligado, después de su llegada al cargo, el 1 de enero de 2017, el socialista portugués António Guterres a retomar la cuestión de la reforma de la ONU, que sigue sobre el tapete ${ }^{60}$.

Paralelamente al debate y frustración generados por los escasos avances habidos en la necesaria reforma de las estructuras de las Naciones Unidas, y en

57. Las causas del malestar de la Administración Bush con Koffi Annan a causa del enfoque dado por el secretario general de la ONU a la intervención de los EE. UU. en Irak y las razones de su caída quedaron sintéticamente recogidas en el reportaje cit. en la nota 55 de Stanley Meister. Sobre las ambigüedades, en lo concerniente a la aprobación o desaprobación al uso de la fuerza de un Estado contra otros, a la altura de 2005, puede verse el trabajo de GutiérRez Espada, Cesáreo: «El 'uso de la fuerza' en el Informe del Secretario General de las Naciones Unidas, preparatorio de la cumbre de jefes de Estado y de Gobierno (septiembre de 2005)", Revista Electrónica de Estudios Internacionales, 2005, pp. 1-24.

58. 57 «Stephen Schlesinger, investigador y autor de un libro sobre la Institución (La Fundación de las Naciones Unidas), ejemplifica una de esas voces críticas", recordaba el periódico español El País, que reproducía textualmente su duro balance sobre la gestión de Ban-ki-Mon: "Ha sido más efectivo consolidando que impulsando reformas, ha mantenido un perfil muy bajo y tampoco ha sido efectivo a la hora de tomar medidas contra el escándalo de los abusos de las fuerzas de paz". Cit. por Mars, Amanda: "Adiós al mandato amargo de Ban-ki-Moon en la ONU», El País, 18 de septiembre de 2016, en <https://elpais.com/internacional/2016/09/18/estados_unidos/1474163138_721920.html> (C. 19-10-2016).

59. Herranz, Francisco: "António Guterres, una nueva esperanza para la ONU», Sputnik Mundo, 4 de enero de 2017, en <https://mundo.sputniknews.com/firmas/201701041066022021-onu-guterres/> (C. 6-01- 2017); ONU (Sputnik): "Guterres destaca la necesidad de hacer a la ONU más eficaz», Sputnik Mundo, 18-09-2017, disponible en <https://mundo.sputniknews.com /politica/201709181072446777onu-reforma-secretario-general/> (C. 18-09-2017); PozzI, Sandro: "Guterres transforma la ONU con su diplomacia activa", El País, 18-09-2017. Disponible en <https://elpais.com/internacional/2017/09/16/ actualidad/1505564784_473600.html> (C. 18-09-2017).

60. Fondo Fiduciario de las Naciones Unidas para la Seguridad Humana: El concepto de seguridad humana, en <http://www.un.org/humansecurity/es/content/el-concepto-de-seguridad-humana> (C10-12-2017). 
M. ${ }^{a}$ ESTHER MARTÍNEZ QUINTEIRO

LA EXPANSIVIDAD DEL DISCURSO SOBRE EL "DERECHO HUMANO DE SEGURIDAD», UN «DERECHO SÍNTESIS». CONCRECIONES Y ETIOLOGÍA

particular de su obsoleto, excluyente e inoperante Consejo de Seguridad, abocado a la parálisis por su composición, e incapaz por ello de garantizar el «derecho a la seguridad internacional", surgió en la ONU un discurso que planteó una dimensión pretendidamente "nueva" del derecho a la seguridad y de las políticas de seguridad, presentada como más progresista e integradora que las preexistentes. Dicha propuesta se vio fortalecida por el hallazgo de la atractiva denominación de «Seguridad Humana» para el objeto que pretendía desarrollar y por el galvanizador e instrumentalmente productivo enfoque de su implementación.

La Web del Fondo Fiduciario de la ONU para la Seguridad Humana, Fondo creado en 1999 con aportaciones financieras fundamentalmente de Japón, a la sazón deseoso de ser aceptado como miembro del Consejo de Seguridad y dispuesto a hacer méritos al efecto, define a día de hoy la "Seguridad Humana» como "un marco normativo dinámico y práctico para hacer frente a las amenazas de carácter intersectorial y generalizado con que se enfrentan los gobiernos y las personas", lo que parece algo así como un "protocolo de actuación frente al riesgo" o un "programa de acción". Si partimos de este texto, el encasillamiento de la "Seguridad Humana " ${ }^{61}$ en alguna de las categorías en las que estamos acostumbrados a pensar, no es fácil. No sabemos si estamos ante un "objetivo", una "acción social» o una "política asistencial otorgada", o una "política social" debida, que son las que derivan de los derechos humanos, o ante un nuevo "derecho humano" proclamado.

La ONU recomienda y promueve la "Seguridad Humana", asociándola a menudo a los derechos humanos, haciéndola aparecer como una especie de panacea cuyo subproducto será la paz, el desarrollo, la «seguridad personal», la «seguridad ciudadana» y la "seguridad internacional», pero en el Derecho Público Internacional, por el momento, no se recoge en Convenio alguno un «Derecho Humano" denominado así. Si queremos considerar tal a la "Seguridad Humana", habrá que aclarar que dicho "valor» es configurado solo en su "discurso propositivo".

Los documentos de las Naciones Unidas definen de varias maneras la «Seguridad Humana: Mientras en algunos textos se apela para explicarla a un lenguaje muy barroco, reiterativo y un tanto abstruso, que produce en el lector cierta confusión, como ocurre con la Web del Fondo Fiduciario de la ONU para la Seguridad Humana, en otros el significado atribuido a ésta no ofrece mayores problemas de comprensión.

En el Documento Final de la Cumbre Mundial 2005 (A/RES/60/1), que en esencia es una declaración de principios y compromisos asumidos por los Estadosmiembro de la ONU, suscrita de los Jefes de Estado y de Gobierno que asistieron a la Cumbre, esta es presentada inequívocamente como un derecho humano:

Subrayamos [dice el Documento en el párrafo 143, como aclaración del epígrafe titulado 'Seguridad Humana'] el derecho de las personas a vivir en libertad y con

61. ONU: Documento Final de la Cumbre Mundial 2005 (A/RES/60/1), en <http://www.un.org/ es/comun/docs/?symbol=A/RES/60/1. (C.1-08-2017) >. 
dignidad, libres de la pobreza y la desesperación...todas las personas, en particular las que son vulnerables, tienen derecho a vivir libres del temor y la miseria, a disponer de iguales oportunidades para disfrutar de todos sus derechos y a desarrollar plenamente su potencial humano ${ }^{62}$.

En 2015, el Fondo Fiduciario de la ONU para la Seguridad Humana y la Dependencia de la Seguridad Humana utilizan este texto para iniciar con él el folleto informativo La Seguridad Humana en las Naciones Unidas, especificando antes que lo que sigue está "orientado por los principios de la Carta de las Naciones Unidas" 63 .

Así pues, en el discurso propositivo de la ONU (recordemos que no es vinculante, solo orientativo) ha ido configurándose un "derecho humano» (universal), de nueva denominación, a que todas las personas vean garantizados todos sus derechos, sean estos civiles o políticos o económicos, sociales y culturales, lo que lo configura como un "derecho de prestación» que exige la implementación de políticas públicas. La sociedad entera, nacional o internacional, es señalada como el sujeto pasivo. La ONU debe esforzarse, en consecuencia, en allegar recursos humanos y financieros para poner en marcha tales políticas allí donde se detecten riesgos, vulnerabilidades, o un vacío de cobertura, pudiendo implicar en la tarea de financiarlas e implementarlas a los Estados, poderes regionales o locales, empresas, ONG, mundo académico, profesionales y organizaciones, en suma representantes de la sociedad civil, seleccionadas a tal fin.

El concepto de "Seguridad Humana" hizo fortuna por primera vez en el marco del Programa de las Naciones Unidas para el Desarrollo (PNUD) ${ }^{64}$, cuando era secretario general de la ONU Butros Ghali ${ }^{65}$, al ser esgrimido por un equipo de técnicos del desarrollo dirigidos por el asesor especial Mahbub ul Haq, responsables

62. Fondo Fiduciario de las Naciones Unidas para la Seguridad Humana. Dependencia de la Seguridad Humana: La seguridad humana en las Naciones Unidas. New York: ONU, 2015, en <htpp// www.un.org/humansecurity/es/content/seguridad-humana-para-todos> (C.1-08-2017).

63. Aunque cabe establecer también sus conexiones con la Carta de la $O N U$ y con las propuestas de la Declaración y Programa de Acción de Viena, aprobados por la Conferencia Mundial de Derechos Humanos el 25 de junio de 1993 que en el Párrafo 6 de la Parte I establecía como objetivos de la ONU la búsqueda de la paz, la seguridad y desarrollo económico y social mediante la promoción del respeto universal y la observancia de los derechos humanos, de conformidad con la Carta de la ONU.

64. Toda la prensa, con motivo de la muerte de Butros Ghali, insistió en un balance de su gestión centrado en el fracaso de la ONU para garantizar la paz y la seguridad en escenarios de conflicto con motivo de las grandes turbulencias de la época (1992-1996), destacando en particular su impotencia o inacción ante la desintegración de Yugoslavia, o la guerra civil de Somalia iniciadas en 1991 o el genocidio de Ruanda en 1994.

Ver por ejemplo la noticia de González Ricard, «Muere el ex secretario general de la ONU Butros-Gali». El País. 17-02-2016, en https://elpais.com/internacional/2016/02/16/ actualidad/1455637665_661495. html (C. 5-08-2017), o el obituario de Carrión, Francisco: «EGIPTO. Muere Butros Ghali, ex secretario general de la ONU. El Mundo.es.16/02/2016. Disponible en http://www.elmundo.es /internacional/2016/02/16/ 56c342cde2704e8d458b4639.html. (C. 5-08-2017)

65. 
M. ${ }^{a}$ ESTHER MARTÍNEZ QUINTEIRO

LA EXPANSIVIDAD DEL DISCURSO SOBRE EL "DERECHO HUMANO DE SEGURIDAD», UN «DERECHO SÍNTESIS». CONCRECIONES Y ETIOLOGÍA

de la elaboración del Informe del PNUD sobre el Desarrollo Humano de $1994^{66}$, que se proponían mostrar las estrechas relaciones entre desarrollo, paz y seguridad y cambiar el concepto prevalente de seguridad:

El concepto de seguridad [lamentaba dicho Informe] se ha interpretado en forma estrecha durante demasiado tiempo: en cuanto seguridad del territorio contra la agresión externa, o como protección de los intereses nacionales en la política exterior o como seguridad mundial frente a la amenaza de un holocausto nuclear. La seguridad se ha relacionado más con el Estado-nación que con la gente...

En el plano mundial la seguridad humana no significa ya contar con salvaguardias cuidadosamente erigidas contra la amenaza de un holocausto nuclear, una probabilidad que se ha reducido grandemente al terminar la guerra fría. En cambio, significa responder a la amenaza de la pobreza mundial que atraviesa las fronteras internacionales en forma de estupefacientes, VIH/SIDA, cambio climático, migración ilegal y terrorismo. La perspectiva del suicidio colectivo al recurrir en forma impulsiva a las armas nucleares fue siempre exagerada. Pero la amenaza de la pobreza mundial que afecta a todas las vidas humanas -en los países ricos y los países pobres- es auténtica y persistente. Y no hay salvaguardias mundiales contra esas amenazas verdaderas a la seguridad humana. El concepto de seguridad debe cambiar así en forma urgente en dos sentidos fundamentales: Del acento exclusivo en la seguridad territorial a un acento mucho mayor en la seguridad de la población. De la seguridad mediante los armamentos a la seguridad mediante el desarrollo humano sostenible. La lista de amenazas contra la seguridad humana es larga, pero la mayoría de ellas pueden agruparse en siete categorías principales:

- Seguridad económica

- Seguridad alimentaria

- Seguridad en materia de salud

- Seguridad ambiental

- Seguridad personal

- Seguridad de la comunidad

- Seguridad política67.

66. "Informe sobre Nuevas Dimensiones de la Seguridad Humana". Cap. 2 del Informe sobre el Desarrollo Humano, publicado para el Programa de Naciones Unidas para el Desarrollo, Fondo de Cultura Económica: México, 1994, p. 28, disponible en <https://derechoalaconsulta.files.wordpress. com/2012/02/pnud-informe-1994-versic3b3n-integral.pdf> (C.2-08-2017).

67. En 1999 se crea el Fondo Fiduciario de las Naciones Unidas para la Seguridad Humana, con fondos aportados por Japón, y la Red de Seguridad Humana, formada por 13 ministros de Asuntos Exteriores, comprometidos a dar a sus políticas de seguridad el enfoque holístico y pacificador de la Seguridad Humana. En el 2000 se crea la Comisión de la Seguridad Humana, para proporcionar a este principio apoyos y planes de implementación. En 2003 se crea una Junta Consultiva Asesora. En el 2004 se establece la Dependencia de la Seguridad Humana, para promocionar la idea. En el 2006 se crea, con Estados y Organizaciones Internacionales, el Grupo de Amigos de la Seguridad Humana. En diciembre de 2010 Ban-ki- Mon nombra un Asesor Especial de la Seguridad Humana, recayendo el cargo en el diplomático japonés Yukío Takasu. 
M. ${ }^{a}$ ESTHER MARTÍNEZ QUINTEIRO

LA EXPANSIVIDAD DEL DISCURSO SOBRE EL "DERECHO HUMANO DE SEGURIDAD», UN «DERECHO SÍNTESIS». CONCRECIONES Y ETIOLOGÍA

Kofi Annan no desestimaba el "uso de la fuerza», ni creía que la "seguridad internacional» pudiera prescindir en todo caso de la misma o que las políticas de desarrollo fueran una alternativa suficiente para garantizarla, es más, autoinculpándose por su inacción en Ruanda cuando fue coordinador de las fuerzas de paz de la ONU entre 1993 y 1994, se erigió en defensor de "la obligación internacional de proteger», aunque pretendía que toda intervención militar pasara por la autorización o ratificación del Consejo de Seguridad de la ONU, pero viendo en el sugestivo discurso de los técnicos del desarrollo una oportunidad para modernizar y mejorar la imagen de la anquilosada ONU, lo acogió con entusiasmo, haciéndolo suyo, completándolo y empleando toda su capacidad de seducción para difundirlo en el espectacular escaparate de la Cumbre del Milenio del año 2000, donde amalgamó la defensa de la Seguridad Humana con la de los principios inspiradores de la Declaración del Milenio, planteando su complementariedad, pues, no casualmente, los "Objetivos del Milenio" 68 buscan lo que los mecanismos creados para implementar la Seguridad Humana ofrecen. Más tarde negociaría el visto bueno de los Estados-Miembro de la ONU a esta operación discursiva, logrando que la importantísima Cumbre Mundial 2005 en su Documento Final hiciera suyo el compromiso de promover la "Seguridad Humana".

El 8 de marzo de 2010, publicó el nuevo Secretario General Ban-ki-Món su Primer Informe sobre Seguridad Humana, en el que solicitó que fuera considerada una de las prioridades de la ONU definir inequívocamente los contenidos de dicho principio y promoverlo. Atendiendo a sus requerimientos, el 27 de julio del mismo año aprobó la Asamblea General de la Organización la prosecución del debate conceptual sobre los contornos de lo que la Cumbre había definido como «Derecho Humano", intentando llegar a un acuerdo internacional al respecto. Diversas iniciativas del secretario general mantuvieron viva la llama y, en abril de 2012, Ban-ki-Món elaboró el Segundo Informe sobre la Seguridad Humana. El 4 de junio la Asamblea General del ONU convocó una asamblea Plenaria para examinarlo y el 10 de septiembre se acordó por la Asamblea dar a la Seguridad Humana un "entendimiento común", es decir definirla institucionalmente.

Las publicaciones de la ONU tienden a presentar esta iniciativa como una prueba de la creatividad y eficacia de la Organización, que, en el arranque del último milenio, impulsó la creación en las Naciones Unidas de una serie de instituciones especializadas, y dotadas de recursos, puestas en pie y movilizadas gracias a la cooperación económica y de gestión entre la ONU y una red de organizaciones externas, promoviendo así novedosas políticas públicas internacionales de seguridad, fundamentalmente preventivas de riesgos de enfermedades, hambrunas, crisis climáticas o conflictos y, o, si estos se hubieran dado ya, orientadas a la restauración de espacios devastados pero también a la estimulación del desarrollo autosostenible en los espacios locales objeto de intervención. Sus promotores, tras detectar lugares particularmente necesitados de atención y estimular la formación

68. ONU: La seguridad humana en las Naciones Unidas, op. cit., p. 9. 
M. ${ }^{a}$ ESTHER MARTÍNEZ QUINTEIRO

LA EXPANSIVIDAD DEL DISCURSO SOBRE EL "DERECHO HUMANO DE SEGURIDAD», UN «DERECHO SÍNTESIS». CONCRECIONES Y ETIOLOGÍA

y empoderamiento de fuerzas locales conocedoras de los problemas o riesgos concretos en cada escenario de acción, buscan la colaboración de voluntarios y de representantes de la sociedad civil, señalados como colaboradores de primer orden por la Declaración del Viena de 1993 y llamados ya a asumir esta misión por la Declaración del Milenio del año 2000. Estos deben implicarse en las tareas de formación profesional de futuros operadores locales, educación cívica, recuperación material y promoción del crecimiento de la productividad de los colectivos vulnerables o de víctimas de catástrofes. Con tal filosofía, en 2015 el Fondo Fiduciario Internacional de Seguridad Humana, había financiado más de 220 proyectos, en más de 85 países, que gracias al nuevo enfoque "asegurador» y empoderador requerido, pretenden rebasar el planteamiento meramente asistencial y pasajero de la acción. En principio parece que fuera de agradecer esta estrategia, aunque habrá que esperar al paso del tiempo para una valoración más ajustada de lo que esta fórmula de cooperación con la sociedad civil da de sí, de sus beneficiarios reales, y de sus posibles costos colaterales en términos de tráfico de influencias en el marco de las Naciones Unidas. No podemos olvidar algunas de las carencias y aún decepcionantes contrapartidas del "Pacto Mundial» (UN Global Compact) también presentado por Kofi Annan en el Foro Económico Mundial de Davos en 1999, para "dar una cara humana al mercado global», que responde a la misma filosofía de movilización voluntarista de la sociedad civil para construir un mundo mejor.

Cabe preguntarse, más allá de si los resultados de estas iniciativas serán finalmente los anunciados, por qué reveló de pronto un potencial dinamizador tan inusitado el concepto de "Seguridad Humana", ciertamente biensonante, pero que ya había sido usado antes de los años 90 alguna vez, y hemos de dar cuenta de cuál es la novedad que comporta y el "valor añadido" que su utilización pretende reportar $^{69}$. ¿Ha entrañado alguna ventaja la reciente postulación del «Derecho a la Seguridad Humana»? ¿Merecería la pena exigir que se juridifique un "Derecho" tan profusamente presente hoy en el discurso propositivo de la ONU?

En realidad, si acabara cristalizando en el plano normativo la aparición de un derecho que llevara el indicado nombre, podría ser considerado como una muestra más de la expansividad y progresividad del discurso de los derechos humanos en general, y podría tener un efecto pedagógico o educativo saludable, pues no está mal que reflexionemos, estimulados por las connotaciones motivadoras que la denominación en boga comporta, sobre la imperatividad y la ejecutividad de los derechos de segunda generación, que cada día se van viendo más claras, pero que aún sufren, en el plano teórico, las consecuencias del posibilismo y la relativización pragmática de los textos de derechos humanos vigentes. Bueno es también que la afirmación del "Derecho a la Seguridad Humana" nos recuerde, como nos recuerda, las causas socio-económicas de muchas de las inseguridades que padecemos, aunque no sean, desde luego, las únicas y todo reduccionismo sea igualmente peligroso.

69. Ob. cit.: p. 9 
Ahora bien, hemos de reconocer que el derecho más arriba mencionado, por el momento, solo "proclamado", pero no positivado, es más una re-denominación afortunada de otro preexistente, o una síntesis de las varias dimensiones ya reconocidas del «Derecho Humano a la Seguridad», que un Derecho realmente nuevo.

Cuando se subraya que el «Derecho de Seguridad Humana" subsume todos los derechos, y se supone que eso es ventajoso, podríamos recordar que, como vimos antes, la Constitución Francesa de 1793 ya había definido la seguridad como el derecho de toda persona a ver garantizados todos los derechos, y, sobre todo, que en el artículo 55 de la Carta de la ONU, esa sí vigente, la «seguridad internacional", que se le encomienda proteger a aquella, requiere explícitamente "la promoción de niveles de vida más elevados, trabajo permanente para todos, y condiciones de progreso y desarrollo económico y social" y la "solución de los problemas internacionales de carácter económico, social y sanitario y otros problemas conexos, procurando la cooperación internacional para elevar la cultura y mejorar la educación, así como para hacer posible el respeto universal a los derechos humanos y a las libertades fundamentales de todos". También anticipamos aquí que una lectura atenta del artículo 28 de la Declaración Universal de 1948, permite ver que la «seguridad internacional«, o, en todo caso, el derecho a un orden social y e internacional justo, se concibe como un derecho multidimensional de la persona, el derecho a que se le garanticen los demás derechos.

Visto así, el "Derecho a la Seguridad Humana" es una versión rebautizada del "Derecho humano a la Seguridad" en general y a la "Seguridad Internacional" o a «un Orden Social e Internacional justo" en particular, aunque, bien mirado, finalmente podría interesar su juridificación si, a la hora de proceder a la misma, se lo configurara no solo como un derecho individual, sino también como un derecho colectivo. Por todo lo dicho, este reciente «hallazgo semántico" de la ONU, añade valor, o pudiera añadirlo, a mi modo de ver, al discurso preexistente de los Derechos Humanos, y desde luego, todo que hagamos para luchar contra los insoportables niveles de violencia, miseria, enfermedad, violencia, etc. será siempre poco, así que bueno será que innovemos para corregir tanto horror.

Otra cosa es que sea verdad la afirmación- que aparece, por ejemplo, en el Informe de 2004 sobre Un mundo más seguro, la responsabilidad que comparti$\operatorname{mos}^{70}$ - de que es el crecimiento de la inseguridad y entidad de las nuevas amenazas del siglo xxi, las que han motivado el llamativo montaje discursivo de la Seguridad Humana y el programa de reformas institucionales aplicado en poco tiempo para promoverla por Kofi Annan y Ban-ki-Món, habiéndose producido entre el 2000 y 2012. No lo es, por convincente y lógico que parezca.

Pese a la entidad e importancia de algunos conflictos desencadenados en el tránsito del siglo xx al xxi, que la ONU no fue capaz de resolver, algunos teóricos, como el británico Max Roser, economista de la Universidad de Oxford, sostienen que, globalmente, las amenazas o los daños, ciertamente graves, a las que los

70. Roser, Max: Our World In Data. En: <https://ourworldindata.org/> (C. 6-05-2017) 
hombres se están enfrentando, lejos de acrecentarse, disminuyen. Para demostrarlo ha creado una influyente plataforma, denominada Our World in Data ${ }^{71}$ donde recoge datos estadísticos sobre educación, cultura, alimentación, economía, salud, morbilidad, medio ambiente, sistemas políticos, y hasta violencia y guerra ${ }^{72}$, entre otros, y concluye que nuestra percepción de empeoramiento de las condiciones de vida de la humanidad es errada.

En la misma línea, en el año 2011, el profesor canadiense de Harward ${ }^{73}$ Steven Pinker, psicólogo por igual celebrado y denigrado por sus abundantes lectores y críticos, publicó el muy conocido libro The Better Angels of Our Nature: Why Violence has Declined ${ }^{74}$. En él redundó en la idea de que durante miles de años la violencia en el mundo ha estado disminuyendo gradualmente, al punto que podría sostenerse que posiblemente estemos viviendo «la era más pacífica de nuestra historia" (aunque reconoció que dicha tendencia no estaba totalmente libre de riesgo de involuciones potenciales y de facto se había visto coyunturalmente interrumpida por picos de violencia, como los correspondientes, en pleno siglo xx, a las dos Guerras Mundiales). Pinker atribuye la percepción que estima distorsionada del supuesto aumento de la inseguridad al crecimiento de la información sobre el acontecer.

También recientes informes de la $\mathrm{ONU}^{75}$, impulsora en el arranque del siglo xxi de la fijación de los Objetivos del Milenio (ODM) y vigilante de su cumplimiento, muestran un optimismo bastante llamativo acerca de la evolución mundial de los parámetros de desarrollo propuestos como meta y evaluados periódicamente ${ }^{76}$,

71. Roser, Max: "La historia visual del a disminución de la guera y la violencia», Our World In Data. En: <https://ourworldindata.org/slides/war-and-violence//> (C. 6-05-2017).

72. Pronto se publicó una versión en español del libro titulada: Los ángeles que llevamos dentro. El declive de la violencia y sus implicaciones. Barcelona: Paidós, 2012.

73. Ibidem, nota 67.

74. Según el Departamento de Información Pública de la ONU «el Informe sobre los Objetivos de Desarrollo del Milenio, una evaluación anual del progreso mundial y regional hacia la consecución de los Objetivos, refleja los datos más exhaustivos y actualizados compilados por más de 27 organismos internacionales y de las Naciones Unidas. Lo elabora el Departamento de Asuntos Económicos y Sociales de las Naciones Unidas». Cit en Comunicado de prensa del Informe de 2015 sobre los Objetivos de Desarrollo del Milenio. Publicado por el Departamento de Información Pública de las Naciones Unidas_DPI/2594/1 S, disponible en <http://www.un.org/es/millenniumgoals/pdf/2015/mdg_2015_ pr_overview_spanish.pdf> (C. 6 de mayo de 2017).

75. ONU: Objetivos de Desarrollo del Milenio. Informe de 2015. <http://www.un.org/es/millenniumgoals/pdf/2015/mdg-report-2015_spanish.pdfht (C. 5-05-2017)>.

76. "Tan solo hace dos escasos decenios, casi la mitad del mundo en desarrollo vivía en la pobreza extrema. El número de personas que ahora viven en la pobreza extrema ha disminuido en más de la mitad, de 1.900 millones en 1990 a 836 millones en 2015. El mundo también ha sido testigo de una mejora espectacular en la igualdad de género en la escolarización desde la introducción de los ODM; la paridad de género en la escuela primaria se ha conseguido en la mayoría de los países. Ahora hay más niñas en las escuelas y las mujeres han ganado terreno en la representación parlamentaria en casi el 90\% de los 174 países que disponen de datos de los 20 últimos años. La proporción media de mujeres en el parlamento prácticamente se ha duplicado durante el mismo período. La tasa de mortalidad de niños menores de 5 años ha descendido en más de la mitad, pasando de 90 a 43 muertes por 
de los que la seguridad, o al menos ciertas manifestaciones de la misma, depende en buena parte.

Desde la puesta en marcha en el año 2000 de los ODM [decía textualmente el Comunicado de prensa del Informe de 2015 sobre dichos Objetivos] $]^{77}$ los esfuerzos concertados de los gobiernos nacionales, la comunidad internacional, la sociedad civil y el sector privado han ayudado a acrecentar la esperanza y las oportunidades para las personas de todo el mundo, y han arrojado resultados espectaculares ${ }^{78}$.

Por su parte los sucesivos Informes sobre la Seguridad Humana de 2005, 2006 y 2007 y 2009/2010, 2012 y 201379, del mismo modo que el Miniatlas de la Seguridad Humana ${ }^{80}$, publicado en 2008, insistían en que tanto el número de conflictos bélicos interestatales o internacionales, como el de guerras civiles, las muertes por terrorismo y los homicidios, han decrecido a partir de los años 90, lo que, hasta 2013, parecía proporcionar razones para ser optimistas, si bien cautelosamente, sobre el futuro de la seguridad mundial. Parecía.

Ciertamente, las cosas están cambiando en nuestros días para peor: las guerras aumentan, el terrorismo y le narcotráfico arrecian ${ }^{81}$, el horizonte de terror

cada 1.000 niños nacidos vivos desde 1990. Las cifras referentes a la mortalidad materna muestran una reducción del 45\% en todo el mundo, descenso que se produjo principalmente a partir del año 2000. Las inversiones dirigidas concretamente a combatir enfermedades como el VIH/SIDA y el paludismo han dado resultados sin precedentes. Las nuevas infecciones por el VIH se redujeron aproximadamente en un 40\% entre los años 2000 y 2013. Más de 6,2 millones de muertes por paludismo se han evitado entre 2000 y 2015, al tiempo que se estima que las intervenciones de prevención, diagnóstico y tratamiento de la tuberculosis salvaron 37 millones de vidas entre 2000 y 2013. En todo el mundo, 2.100 millones de personas han obtenido acceso a servicios mejorados de saneamiento y la proporción de personas que practican la defecación al aire libre ha descendido en casi la mitad desde 1990. La asistencia oficial para el desarrollo procedente de los países desarrollados registró un aumento del 66\% en términos reales entre 2000 y 2014, hasta alcanzar los 135.200 millones de dólares».

ONU: Comunicado de prensa del Informe de 2015 sobre los Objetivos de Desarrollo del Milenio, cit.

\section{Idem}

78. Todos ellos están disponibles y pueden consultarse en la web del Grupo de Investigación que desarrolla, desde el año 2005, el Proyecto, <http://www.hsrgroup.org/> (1-05-2017).

79. EquiPo Editorial: Miniatlas de la seguridad humana. Mayol Banco Mundial, 2008, disponible en <http:// www. hsrgroup.org/our-work/publications/miniatlas.aspx> (C. 1-05-2017).

80. Jean-Marie Guéhenno sostiene que «el mundo está iniciando su etapa más peligrosa desde hace décadas. El marcado incremento de las guerras en los últimos años está desbordando nuestra capacidad de afrontar las consecuencias. Desde la crisis mundial de los refugiados hasta la extensión del terrorismo, nuestro fracaso colectivo a la hora de resolver conflictos está engendrando nuevas amenazas y emergencias. Incluso en sociedades pacíficas, la política del miedo está provocando una polarización y una demagogia muy peligrosas». GuéHenno, Jean-Marie: The Fog of Peace: A Memoir of International Peacekeeping in the 21st Century. Washington: Brooking Institucion Press, 2015.

81. Los resultados del Quinto Informe del IPCC (Intergovernmental Panel on Climate Change, en español conocido como Grupo Intergubernamental sobre el Cambio Climático, creado por la Organización Meteorológica Mundial y el Programa de Naciones Unidas sobre Medio Ambiente) AR5, terminado en 2014, resultan bastante alarmantes. Los expertos señalan que «muchos de los cambios observados desde la década de 1950 no tienen precedentes en décadas ni en milenios». Cambio Climático: 
nuclear se ennegrece, la crisis climática se agudiza ${ }^{82}$, el hambre hace estragos ${ }^{83}$ y en 2017 la ONU afirma ya que el mundo se enfrenta a la mayor crisis humanitaria desde el fin de la Segunda Guerra Mundial ${ }^{84}$.

La aparición del discurso sobre el "Derecho a la Seguridad Humana" y la implementación de los mecanismos específicos para efectivarlo, sin esperar a que su positivación se produjera, fue previa a esta terrible involución descrita, no fue por tanto el fruto de la misma y no la impidió.

Es más, no es ahora, precisamente, cuando es más necesario que nunca preservar los Derechos Humanos, aunque no puedan resolverlo todo, cuando el respeto a los mismos se refuerza. Más bien están siendo objeto de cuestionamiento

Informe de síntesis. Guía Resumida del Quinto Informe de Evaluación del IPCC, en <https://fundacionbiodiversidad.es/sites/default/files/informacion-institucional/guia-sintesis-definitiva.pdf>.

82. FAO: «Vuelve a crecer el hambre en el mundo, impulsada por los conflictos y el cambio climático, según un nuevo informe de la ONU», en Noticias. FAO, 2017. Disponible en <http://www.fao. org/news/story/es/item/1037465/icode/>.

83. REDACCIÓN BBC: "Por qué la ONU asegura que el mundo está atravesando 'la mayor crisis humanitaria' desde la Segunda Guerra Mundial». El Mundo, 11 marzo 2017.

84. Los Estados-miembros de la ONU pueden de facto elegir qué parte del corpus de Derechos Humanos juridificados tienen a bien aceptar, pues se les permite seleccionar los Convenios o Protocolos (en que estos van plasmando de modo segmentado) que desean ratificar, previamente segregados del todo, estrategia diseñada precisamente para lograr, como mal menor, adhesiones sectoriales a tales derechos, y aún les será tolerado a los Estados hacer reservas sobre exigencias concretas, que no deseen asumir, contenidas en los Convenios ratificados, pese a la recomendación de la Declaración y Programa de Acción de Viena, aprobados por la Conferencia Mundial de Derechos Humanos el 25 de junio de 1993 (Párrafo 5 de la Parte II) que dicha práctica fuera eliminada o al menos limitada lo más posible.

La extendida defensa del carácter actualmente «vinculante» de la Declaración Universal de los Derechos Humanos de 1948 para todos los Estados de la ONU, que parte de la afirmación de su conversión en "derecho consuetudinario", y que la Proclamación de Teherán, elaborada por la Primera Conferencia Mundial de Derechos Humanos, de 1968, declaró "obligatoria", no resulta contrapeso suficiente a la fragmentación de los compromisos estatales con tales derechos propiciada por las prácticas antes apuntadas, por varias razones: Primero, porque no todos aceptan el carácter vinculante (sobrevenido) de la antedicha Declaración [que la UNESCO califica prudencial y significativamente de "Semivinculante». UNESCO: Más sobre la naturaleza y el estatus de los instrumentos legales y programas, <http://www.unesco.org/new/es/social-and-human-sciences/themes/advancement/networks/ larno/legal-instruments/nature-and-status/> (C. 30-12-2017)]. Segundo, porque esta última no contiene el total de los Derechos hoy especificados en los Convenios. Tercero porque carece de órgano que controle y garantice su cumplimiento. De ahí la enfatización compensatoria del discurso propositivo de la indivisibilidad y la interdependencia de los Derechos Humanos [efectuado por la Asamblea General de Naciones Unidas en su Resolución 421 E (V) de 1950 sobre el Proyecto del Pacto Internacional de Derechos del Hombre y Medidas Aplicación: Labor futura de la Comisión de Derechos del Hombre, y en su Resolución 32/130 de 1977 sobre Distintos criterios y medios posibles dentro del sistema de las Naciones Unidas para mejorar el goce efectivo de los Derechos Humanos y las libertades fundamentales, y reiterado en el Párrafo 13 de la Proclamación de Teherán de 1968 y en el Párrafo 5 de la Parte I de la Declaración y Programa de Acción de Viena de 1993, que, por cierto, evitó reconocer carácter imperativo a la Declaración de 1948]. La propuesta y defensa enfática de «derechos síntesis» -como es el caso del "Derecho a la Paz" o del "Derecho a la Seguridad Humana»- contribuye a reforzar el discurso de la interdependencia e indivisibilidad del conglomerado de los Derechos Humanos. 
y se debilitan las adhesiones a estos principios, como consecuencia de la crecida del miedo.

Sin negar que el discurso del "Derecho a la Seguridad Humana" promovido por los burócratas de la ONU y acogido por los Estados llamados a secundarlo, y las políticas públicas internacionales articuladas para implementarlo, pueden dejar, al margen de las contrapartidas potenciales no deseables, alguna cosa positiva, como dije ya, si atendemos a su cronología, debemos concluir que su aparición debió responder a otra cosa que a la crecida de riesgos y amenazas alegadas para explicar la razón de ser de dicha iniciativa. Creo que fue una operación legitimadora, destinada a compensar el trascendente fracaso de la reforma estructural de la ONU y, con ella, de su misión aseguradora, y a mejorar su deteriorada imagen.

Por otra parte, al recuperar y patentizar el carácter englobador del "Derecho Humano a la Seguridad» (Derecho del ser humano a estar seguro de que todos sus Derechos universales le serán reconocidos y garantizados), especialmente visibilizado en el curso de esta operación re-denominadora que subyace a la enunciación del "Derecho a la Seguridad Humana", su dimensión más expansiva, aflora y patentiza su naturaleza de "Derecho-Síntesis", constructo que constituye un contrapeso corrector de la paradójica fragmentación del compromiso con el Derecho Público Internacional de los Derechos Humanos, permitida procedimentalmente a los Estados-miembros de las Naciones Unidas ${ }^{85}$.

85. 